\title{
Material Properties of Human Rib Cortical Bone From Dynamic Tension Coupon Testing
}

\section{Andrew Robb Kemper}

\author{
Thesis submitted to the faculty of the \\ Virginia Polytechnic Institute and State University \\ in partial fulfillment of the requirements for the degree
}

Master of Science

in

Mechanical Engineering

\author{
Stefan M. Duma, Ph.D., Chair \\ H. Clay Gabler, Ph.D. \\ Joel D. Stitzel, Ph.D.
}

April 22, 2005

\section{Blacksburg, Virginia}

Keywords : Thorax, Thoracic Injury, Bone Biomechanics, Rib, Stress, Strain, Tension 


\title{
Material Properties of Human Rib Cortical Bone From Dynamic Tension Coupon Testing
}

\author{
Andrew R. Kemper
}

\begin{abstract}
The purpose of this study was to develop material properties of human rib cortical bone using dynamic tension coupon testing. This study presents 117 human rib cortical bone coupon tests from six cadavers, three male and three female, ranging in age from 18 to 67 years old. The rib sections were taken from the anterior, lateral, and posterior regions on ribs 1 through 12 of each cadaver's rib cage. The cortical bone was isolated from each rib section with a low speed diamond saw, and milled into dog bone shaped tension coupons using a small computer numerical control machine. A high-rate servo-hydraulic Material Testing System equipped with a custom slack adaptor, to provide constant strain rates, was used to apply tension loads to failure at an average rate of $0.5 \mathrm{strains} / \mathrm{sec}$. The elastic modulus, yield stress, yield strain, ultimate stress, ultimate strain, and strain energy density were determined from the resulting stress versus strain curves. The overall average of all cadaver data gives an elastic modulus of $13.9 \mathrm{GPa}$, a yield stress of 93.9 MPa, a yield strain of $0.883 \%$, an ultimate stress of $124.2 \mathrm{MPa}$, an ultimate strain of $2.7 \%$, and a strain energy density of 250.1 MPa-strain. For all cadavers, the plastic region of the stress versus strain curves was substantial and contributed approximately 60 strain \% to the overall response and over 80 strain \% in the tests with the 18 year old cadaver. The rib cortical bone becomes more brittle with increasing age, shown by an increase in the modulus $(\mathrm{p}<0.01)$ and a decrease in peak strain $(\mathrm{p}<0.01)$. In contrast to
\end{abstract}


previous three-bending tests on whole rib and rib cortical bone coupons, there were no significant differences in material properties with respect to rib region or rib level. When these results are considered in conjunction with the previous three-point bending tests, there is regional variation in the structural response of the human rib cage, but this variation appears to be primarily a result of changes in the local geometry of each rib while the material properties remain nearly constant within an individual. 


\section{TABLE OF CONTENTS}

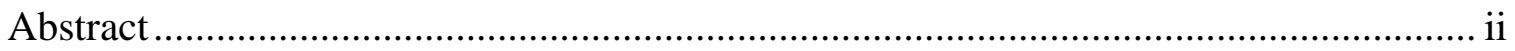

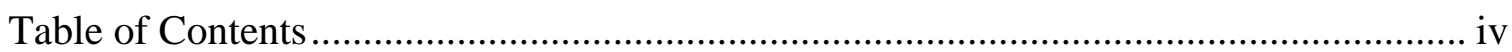

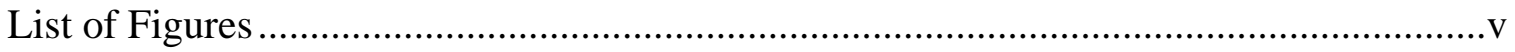

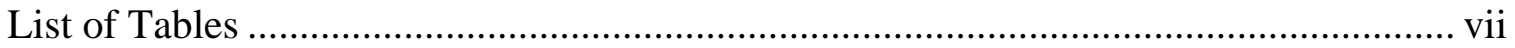

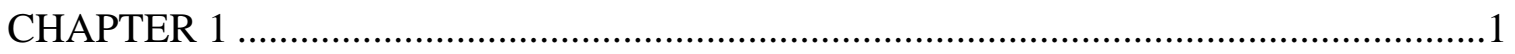

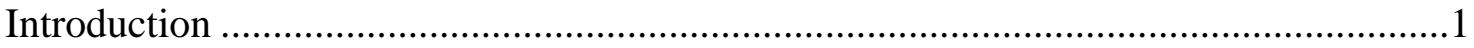

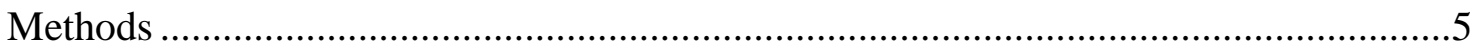

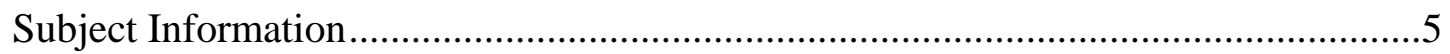

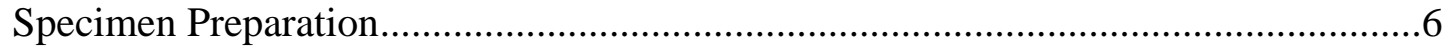

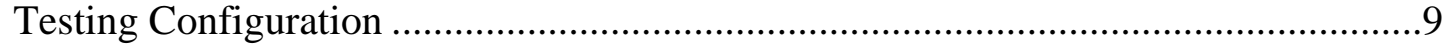

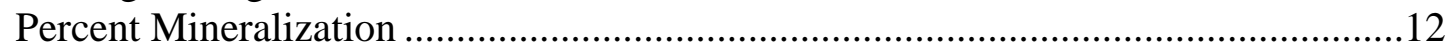

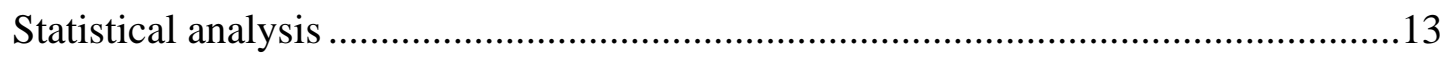

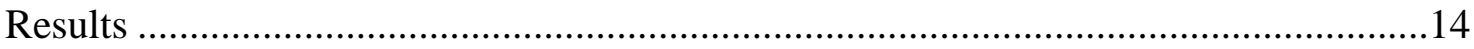

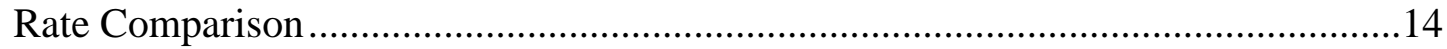

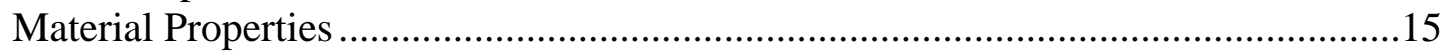

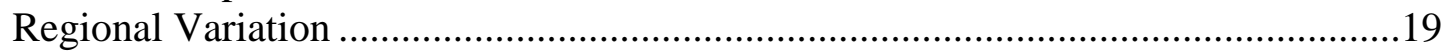

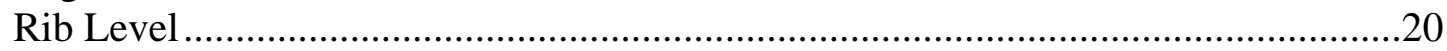

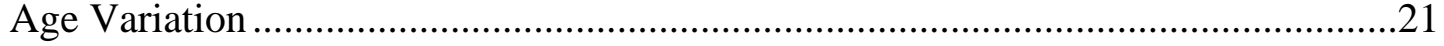

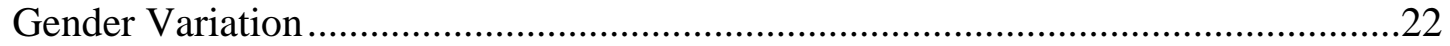

Global Bone Mineral Density ............................................................................23

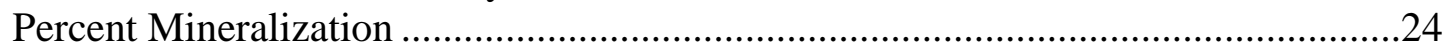

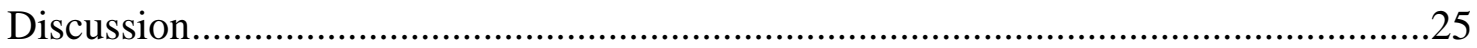

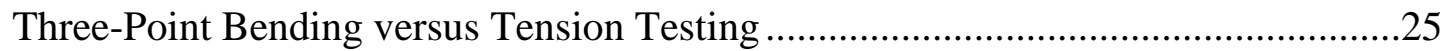

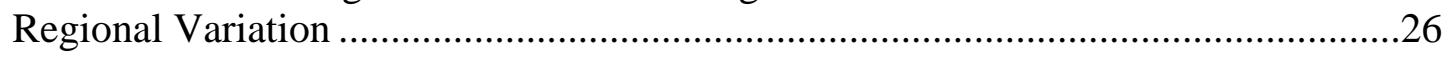

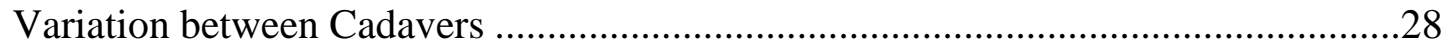

Bone Mineral Density and Percent Mineralization ................................................30

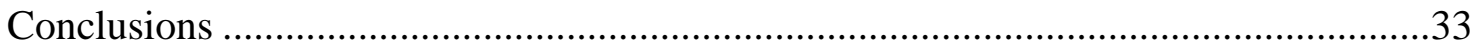

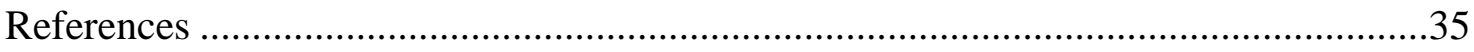

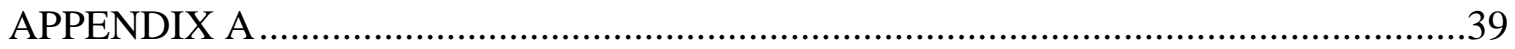




\section{LIST OF FIGURES}

Figure 1: The locations of the rib specimens (anterior and lateral shown twice)................7

Figure 2: Steps to obtain rectangular rib cortical bone coupon. ......................................8

Figure 3: Rib cortical bone ‘dog bone’ tension specimen dimensions (left) and final dog bone tension coupon (right).

Figure 4: Illustration of the slack adaptor : as the MTS shaft moves upward (left), the slack adapter is engaged (middle) and pulls the bone coupon to failure (right)...10

Figure 5: The rib tests utilized the extensometer as the primary strain measurement device and the potentiometer was for redundancy in case of extensometer failure.

Figure 6: Example plot of raw data and different CFC filters showing the elimination of noise without affecting the signal.

Figure 7: Strain rate comparison: dynamic chest compression (Duma, 2005) versus

presented rib tension testing data.

Figure 8: Cadaver 1 anterior section stress versus strain plot.......................................16

Figure 9: Cadaver 2 anterior section stress versus strain plot.......................................16

Figure 10: Cadaver 3 anterior section stress versus strain plot.....................................16

Figure 11: Cadaver 4 anterior section stress versus strain plot......................................16

Figure 12: Cadaver 5 anterior section stress versus strain plot.......................................16

Figure 13: Cadaver 6 anterior section stress versus strain plot..................................... 16

Figure 14: Cadaver 1 lateral section stress versus strain plot. .......................................17

Figure 15: Cadaver 2 lateral section stress versus strain plot. ......................................17

Figure 16: Cadaver 3 lateral section stress versus strain plot. .......................................17

Figure 17: Cadaver 4 lateral section stress versus strain plot. .......................................17

Figure 18: Cadaver 5 lateral section stress versus strain plot. ......................................17

Figure 19: Cadaver 6 lateral section stress versus strain plot. .....................................17

Figure 20: Cadaver 1 posterior section stress versus strain plot.....................................18

Figure 21: Cadaver 2 posterior section stress versus strain plot....................................18

Figure 22: Cadaver 3 posterior section stress versus strain plot.....................................18

Figure 23: Cadaver 4 posterior section stress versus strain plot.....................................18 
Figure 24: Cadaver 5 posterior section stress versus strain plot....................................18

Figure 25: Cadaver 6 posterior section stress versus strain plot....................................18

Figure 26: Average modulus, E, of anterior, lateral, and posterior regions.......................19

Figure 27: Average Ultimate Strain of anterior, lateral, and posterior regions ..................19

Figure 28: Average Ultimate Stress of anterior, lateral, and posterior regions .................19

Figure 29: Average Strain Energy Density anterior, lateral, and posterior regions............19

Figure 30: Average modulus, E ribs 1-12 ..............................................................20

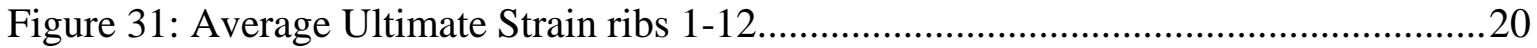

Figure 32: Average Ultimate Stress ribs 1-12.........................................................20

Figure 33: Average Strain Energy Density ribs 1-12.................................................20

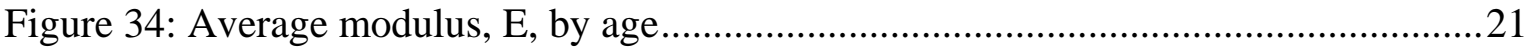

Figure 35: Average Ultimate Strain by age ...........................................................21

Figure 36: Average Ultimate Stress by age .............................................................21

Figure 37: Average Strain Energy Density by age ..................................................21

Figure 38: Average modulus, E, by gender ..........................................................22

Figure 39: Average Ultimate Strain by gender ..........................................................22

Figure 40: Average Ultimate Stress by gender ......................................................22

Figure 41: Average Strain Energy Density by gender ..............................................22

Figure 42: Average modulus, E, by BMD ...............................................................23

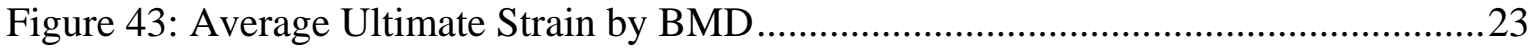

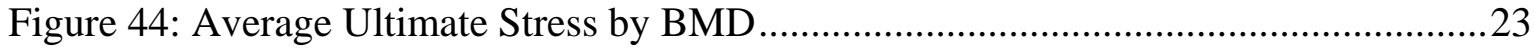

Figure 45: Average Strain Energy Density by BMD..................................................23

Figure 46: Average modulus, E, versus Percent Mineralization ......................................24

Figure 47: Average Ultimate Stress versus Percent Mineralization .................................24

Figure 48: Average Ultimate Stress versus Percent Mineralization ................................24

Figure 49: Average Strain Energy Density versus Percent Mineralization ........................24

Figure 50: Average elastic and plastic strain versus cadaver age .................................29

Figure 51: Normalized average and standard deviations of cross-sectional area, BMD, and percent mineralization for three studies.................................................33 


\section{LIST OF TABLES}

Table 1: Osteogram data for cadavers used in rib cortical bone testing. ..........................6

Table A 1: Material Properties for Cadaver 1.............................................................39

Table A 2: Material Properties for Cadaver 2............................................................ 40

Table A 3: Material Properties for Cadaver 3............................................................. 41

Table A 4: Material Properties for Cadaver 4..............................................................42

Table A 5: Material Properties for Cadaver 5............................................................. 43

Table A 6: Material Properties for Cadaver 6............................................................ 44 


\section{CHAPTER 1}

\section{INTRODUCTION}

In automotive accidents, chest injuries rank second only to head injury in overall number of fatalities and serious injuries (Cavanaugh, 1993). Elhagediab and Rouhana (1998) examined incidents of injuries due to frontal impacts in the National Automotive Sampling System (NASS) from 1988 to 1994, and found that chest injuries constituted $37.6 \%$ of all AIS 3+ injuries, $46.3 \%$ of all AIS $4+$ injuries, and $43.3 \%$ of all AIS 5+ injuries. Schneider (1989) conducted a NASS case study on frontal impacts from 1979 to 1984. His results showed that for both unrestrained drivers and right-side passengers, skeletal injury represented the highest percentage of AIS 3+ injuries. In addition, previous studies using restrained cadavers in impact sled tests have frequently found rib fractures to be the most common skeletal injury (Crandall, 1997; Kaillieris, 1998; Cromack, 1975; Patrick, 1976; Ramet, 1979). Finite element models of the human thorax are becoming an integral tool in the reduction of these injuries, thereby improving crash worthiness. However, the correct biomechanically-based material properties must be applied in order for these models to accurately predict injury.

Numerous authors have investigated the material properties of human cortical bone and the effects of different parameters such as: tension, compression, age, bone mineral density, direction dependence, regional variation, and rate dependence. Dempster (1952) presented one of the first human cortical bone material property studies using coupons taken from human femur and tibia bones. This study conducted tension and compression tests in both the axial and lateral directions. The results showed that the ultimate stress 
and strain was significantly lower in the lateral direction than in the axial direction, and thereby defining cortical bone as a non-isotropic material. However, only quasi-static loading rates were tested. Therefore, viscoelastic effects needed for application to the automobile safety field were not investigated. Evans (1956) performed tests on human femur, tibia, and fibula cortical bone coupons in tension and looked at the effects of regional variation. The results showed that the material properties of cortical bone do, in fact, vary within a single bone. However, like the tests performed by Dempster (1952), these tests were conducted at quasi-static rates and did not examine viscoelastic effects. McElhaney (1965) presented one of the first studies that investigated the effects of various loading rates on human cortical bone. The tests were performed on human femur bone coupons in compression, and showed the trend that as the loading rate increases, the ultimate stress and modulus increase while the ultimate strain decreases. Reilly (1975) performed quasi-static tests on human femur specimens in tension in four loading directions; $0^{\circ}, 30^{\circ}, 60^{\circ}$, and $90^{\circ}$ from the transverse plane. The results showed an increase in ultimate stress and the modulus with increasing angle from the transverse plane. Finally, Saha (1974) conducted dynamic tests but only in the tension along the axis of the bone. Although there has been a great deal of research that has investigated the material properties of human cortical bone through tension and compression testing, the majority of this research has primarily focused on the long bones of the body.

While there has been no attempt to investigate the material properties of the thorax through tension or compression testing, a number of studies have performed three-point bending tests on whole rib sections to evaluate the properties of the ribs. Granik and 
Stein (1973) performed three-point bending tests on 10 human rib specimens from the $6^{\text {th }}$ and $7^{\text {th }}$ rib. After testing, a two centimeter section was removed on either side of the fracture location and photographed. The centroid and moment of inertia were determined by hand from enlarged traces of the photographs. The Young's modulus and failure bending stress were calculated by using linear elastic beam equations. The average modulus of elasticity and average bending stress were found to be $11.5 \mathrm{GPa}$ and 106 MPa, respectively. Yoganandan and Pintar (1998) investigated the properties of the $7^{\text {th }}$ and $8^{\text {th }}$ rib of 30 human cadavers by subjecting $150 \mathrm{~mm}$ long sections of rib to three-point bending. A photograph of the rib cross section, near the point of fracture, was digitized to obtain the centriod, cross-sectional area, and moment of inertia. The Young's modulus was then calculated by using linear elastic beam equations. The average Young's modulus of the seventh and eight ribs were reported to be $2.32 \mathrm{GPa}$ and $188.6 \mathrm{MPa}$, respectively. The mechanical behavior of the ribs was determined to be independent of location, both vertically and horizontally on the thorax over this narrow range.

Unlike previous studies that only evaluated differences between adjacent ribs, Cormier (2005) was the first study to conduct three-point bending tests on a total of 56 whole rib sections taken from anterior, lateral, and posterior sections of ribs 2-12 of four cadavers. Strain was measured by placing a strain gage at the center of the tension side of the rib section. A digital picture of the rib cross section, near the point of fracture, was used to obtain the centriod, cross-sectional area, and moment of inertia. The Young's modulus was then calculated by using linear elastic beam equations. The average modulus, ultimate stress, and ultimate strain were determined to be 17.7 GPa, 135.4 Mpa, $1.38 \%$ 
strain, respectively. In addition, these whole rib three-point bending tests showed regional variation in the structural response with the anterior lower than the lateral and posterior values. This study also illustrated that the geometry of each rib varies by region with the anterior sections having smaller distances from neutral axis and smaller radius of gyration values both of which have the effect of lowering the structural response for the anterior sections.

Stitzel (2003) presented a study examining the regional variation in the material properties of the thorax in conjunction with finite element modeling. In this study dynamic three-point bending tests were performed on small rectangular cortical bone coupons from the anterior, lateral, and posterior locations of the rib cages of four cadavers. Linear elastic bending beam equations were used to calculate the ultimate stress and elastic modulus of cortical bone. Based on the findings of Burstein (1972), the ultimate stress data was divided by a factor of 1.56 to arrive at an estimate of the peak stress allowing for plasticity. Stitzel (2003) found an increase in the average stiffness and average ultimate stress for the cortical bone specimens located in the lateral portion of the ribs versus the anterior and posterior rib locations. The overall average ultimate stress ranged from 116.7 $\mathrm{MPa}$ to $153.5 \mathrm{MPa}$ for the three-point coupon. The overall average elastic modulus ranged from 7.5 GPa to $11.9 \mathrm{GPa}$ for the three-point coupon. It was also shown that stiffness, ultimate stress, and ultimate strain generally increased with increasing rib number. 
Although three-point bending tests provide an indication of the true material properties, they will always be limited by the need to calculate the stress and strain, which requires linear elastic assumptions and correction factors for plasticity, rather than measuring them directly. The ideal method for determining the material properties of cortical bone is tension testing of cortical bone coupons. Therefore, the purpose of this study was to develop material properties of human rib cortical bone using dynamic tensile coupon testing. This method allows for the direct measurement of material properties without the confounding effects of geometry or linear elastic beam theory assumptions.

\section{METHODS}

This study presents 117 human rib cortical bone coupon tests taken from the anterior, lateral, and posterior regions on ribs 1 through 12 from six cadavers, three male and three female, ranging in age from 18 to 67 years old. The methodology is presented in four parts: experimental configuration, presenting the gathering and preparation of human rib cortical bone tension coupons; testing configuration, detailing the MTS setup and measurement devices; percent mineralization, discussing the determination of mineral content in each specimen; and statistical methodology, covering the analysis of variance of the material property data.

\section{Subject Information}

Specimens of unembalmed fresh frozen human rib cortical bone were taken from six cadavers, three male and three female, ranging in age from 18 years to 67 years. For comparison with the standard population, Osteograms were performed on the left hand of each cadaver. The left hand of the cadavers was x-rayed and scanned by CompuMed 
incorporated (Los Angeles, CA). The bone mineral density (BMD) results are reported with respect to the normal population (Table 1). The t-score should be used to compare the cadaver's BMD with that of the general population. In addition, the z-score can be used to compare the BMD of the subjects with the average for their age. A t-score of -1 corresponds to one standard deviation below the mean for the general population, meaning the individual is at or above the $-63^{\text {rd }}$ percentile for BMD, or close to normal. T-scores of 2 and 3 correspond to $97^{\text {th }}$ and $99^{\text {th }}$ percentiles, respectively. Therefore, cadavers 4 and 6 have above average BMD with respect to the average young population; cadaver 3 is very close to average; and cadavers 1 and 2 have below average BMD.

Table 1: Osteogram data for cadavers used in rib cortical bone testing.

\begin{tabular}{|c|c|c|c|c|c|}
\hline Cadaver & Gender & Age & Bone Mineral Density & T-Score & Z-Score \\
\hline 1 & F & 64 & 89.20 & -2.0 & 0.0 \\
\hline 2 & M & 45 & 81.40 & -2.7 & -2.0 \\
\hline 3 & M & 67 & 105.40 & -0.5 & 0.9 \\
\hline 4 & F & 61 & 122.30 & 1.1 & 2.4 \\
\hline 5 & F & 46 & 93.70 & -1.6 & -1.6 \\
\hline 6 & M & 18 & 138.30 & 3.2 & 3.2 \\
\hline
\end{tabular}

\section{Specimen Preparation}

In order to create the bone coupon for tension testing, numerous steps of detailed preparation were required. First, an oscillating bone saw (Standard Autopsy SawBD040, Mopec, Detroit, MI) was used to remove the rib cage from the body as a whole. Next, sections from the anterior, lateral, and posterior regions of the rib cage were cut from each rib level (Figure 1). However, not all of the locations designated in Figure 1 could be obtained from each body due to curvature or insufficient size and or thickness. A low speed diamond saw (South Bay Technology, San Clemente, CA) was then used to cut a rectangular coupon from the rib section with micrometer precision (Figure 2). The 
diamond saw blade was kept in a saline bath and was operated at a low cutting speed to minimize the heat created from friction. The rectangular bone coupon was prepared by first removing the tissue and periosteum from the bone surface. Then the rib section was placed in a bone chuck and mounted to a pivoting arm on the low speed diamond saw. The rib section was cut to the final length with the use of a micrometer which controlled the position of the pivoting arm. Once the specimen was cut to the correct final length, two parallel cuts were made along the axis of the rib specimen on the exterior side.
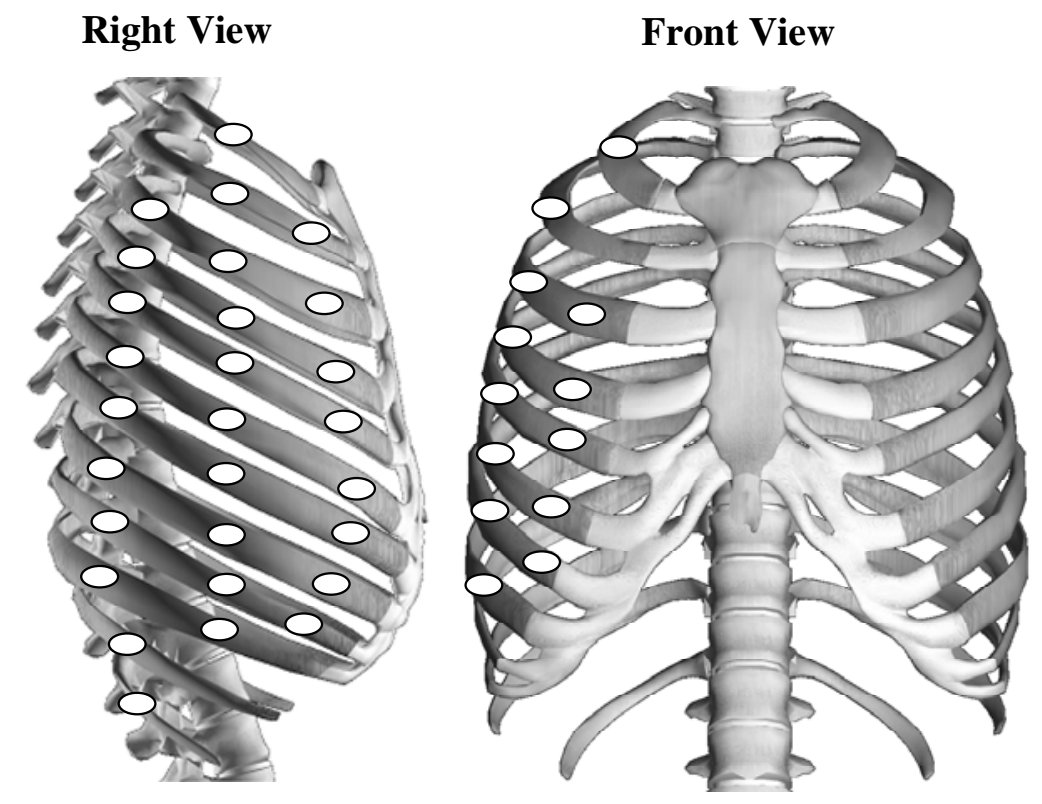

Figure 1: The locations of the rib specimens (anterior and lateral shown twice). 


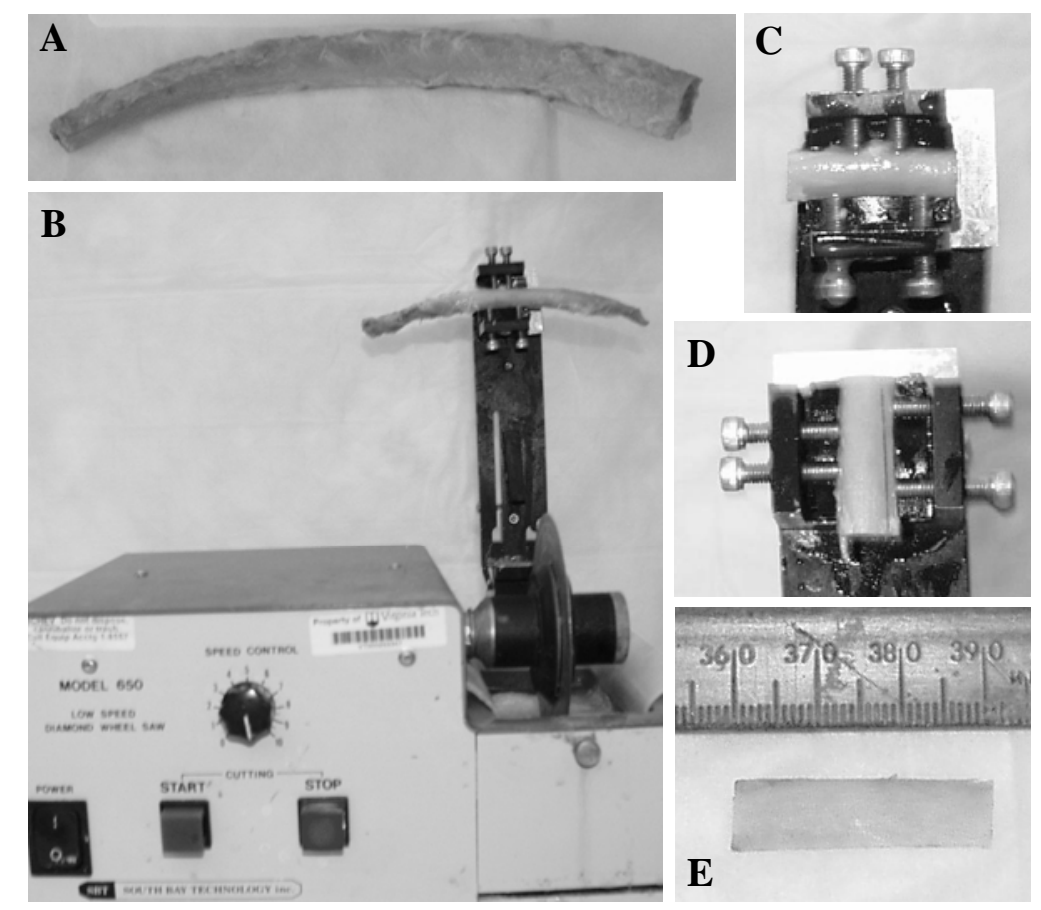

Figure 2: Steps to obtain rectangular rib cortical bone coupon.

A) Anterior, lateral and posterior sections were cut from each rib of the rib cage. B) Rib sections were placed in a bone chuck and mounted to the low speed diamond saw. C) Specimens were cut to the final specimen length. D) Two parallel cuts were made on the exterior side along the axis of the rib to obtain the final specimen width.

E) Rib coupon cut to final dimensions and ready for milling.

The resulting rectangular coupon of rib cortical bone was then milled using a small Computer Numerical Control (CNC) machine (MAXNC 10, MAXNC Inc., Chandler, AZ). Since the rib coupon was cut to the final specimen length and width with the low speed diamond saw, it was necessary to mill a rectangular alignment pocket in the plastic mill base in order to precisely position the rib coupon before clamping. Once the rib coupon was placed in the alignment pocket, a specially designed grip was used to clamp the specimen down for milling. The mill base was contained inside a water tight steel container mounted to the mill base. This container was filled with saline before the specimen was milled in order to keep the specimen cool and wet during the milling process. The mill ran a single code to cut the dog bone contour and drill the alignment 
pin holes in the grips with micrometer precision (Figure 3). Finally, each side of the dog bone specimens where wet sanded with 240,320, 400, and 600 grit sandpaper and measured with calipers until a constant thickness, less than $<0.0254 \mathrm{~mm}$ difference, was obtained throughout the entire specimen.
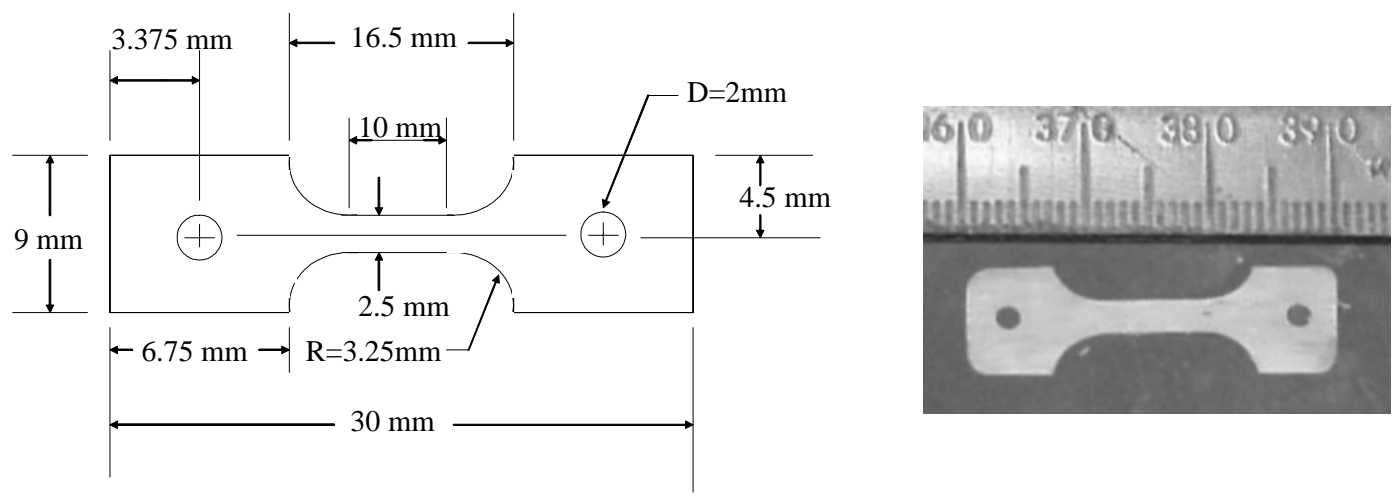

Figure 3: Rib cortical bone ‘dog bone’ tension specimen dimensions (left) and final dog bone tension coupon (right).

\section{Testing Configuration}

A high rate servo-hydraulic Material Testing System (MTS 810, Eden Prairie, MN) machine was used with a custom designed slack adaptor and coupon grips. Additional practice tests were done prior to the final 117 tests in order to develop an accurate testing methodology and desired strain rates for this test series. The tension tests were run using displacement control. Since the MTS requires approximately $1 \mathrm{~cm}$ to accelerate to the desired velocity, a slack adaptor was designed and fabricated to allow time for the machine to reach the desired velocity before pulling the specimen into tension (Figure 4). In addition, this ensures that a constant strain rate is applied to the specimen rather than a range of rates as the MTS reaches the target velocity. 

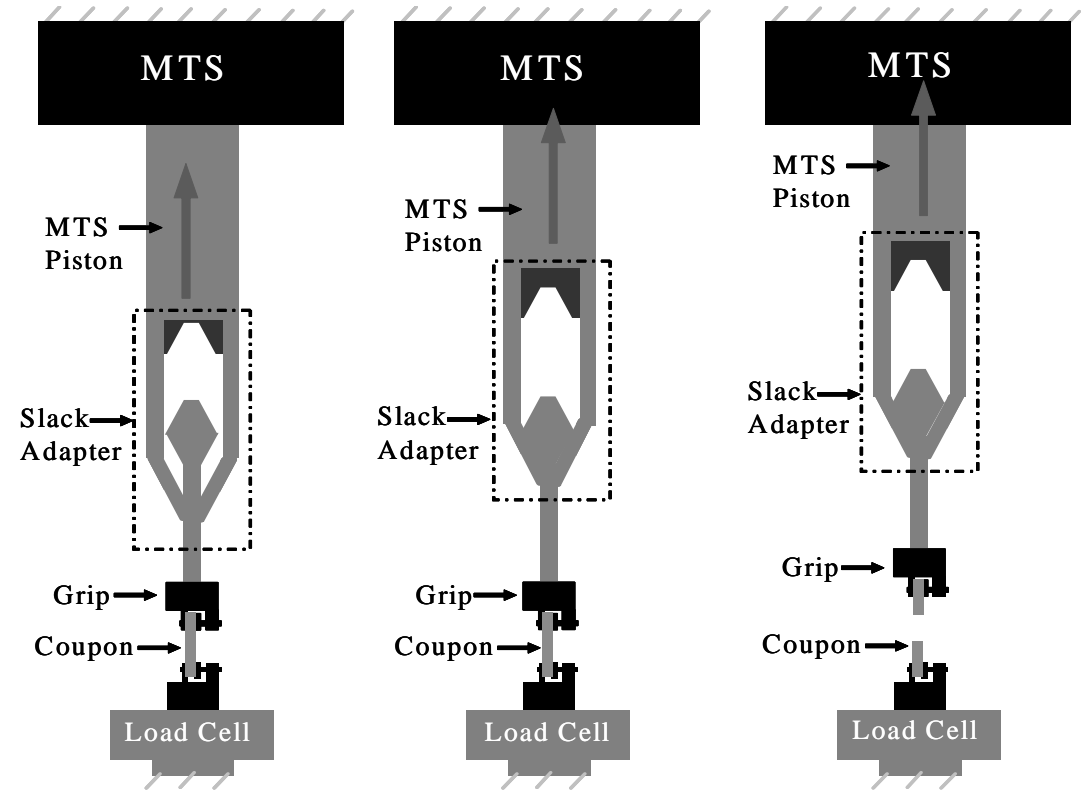

Figure 4: Illustration of the slack adaptor : as the MTS shaft moves upward (left), the slack adapter is engaged (middle) and pulls the bone coupon to failure (right).

The three main sources of misalignment in a material testing setup were addressed in order to minimize variable bending stresses, which result in a reduction in both strength and ductility. As described earlier, extreme care was taken during the specimen preparation process to maintain symmetric machining along the axis of interest of the test specimens. In order to align the centerlines of the top and bottom grips, an aluminum specimen with the same dimensions of the cortical bone coupon specimens was instrumented with strain gages on all four sides of the gage length (ASTM Standard E 1012-99). A dial indicator read the position so the load cell could be adjusted in small increments until the strain gages read within 100 microstrain of one and other, which is less than $1 \%$ of the total loading strain in the tests. The conformance of the specimen centerline to the top and bottom grip centerlines was addressed through design and precise machining of the grips. For tension testing, the grips were designed to use both a 
pin and clamp configuration. The pin ensured proper centerline conformance, and the clamp provided the holding force. To hold the bone coupon in place, the grip screws were tightened forcing metal plates to clamp both ends of the coupon.

Using the MTS and the custom designed slack adapter and grips, the coupons were pulled in tension beyond the point of failure at a target rate of 0.5 strains/s. This rate corresponds to the average strain rate resulting from dynamic seat belt loading of the rib cage (Duma, 2005). For these axial tension failure tests, a $2224 \mathrm{~N}$ load cell was used to measured load (MTS 661.18E-02, 2224 N, Eden Prairie, MN). Displacement was measured with an extensometer (MTS 632.13F-20, 10mm +/-1.5mm, Eden Prairie, MN) placed directly on the gage length of each coupon (Figure 5). The data was collected at 30,000 $\mathrm{Hz}$ and filtered at channel filter class (CFC) 180. Preliminary tests showed that filtering to CFC 180 eliminated noise without effecting the signal. Stress was calculated by dividing the force measurement by the cross sectional area of the specimen gage length. Strain was determined using the Lagrangian formulation of dividing the change in extensometer position by the initial position. The yield point was determined by the intersection of a straight line parallel to the elastic portion of the curve with a $0.2 \%$ offset and the stress-strain curve. The modulus of elasticity was calculated by picking two points, approximately $30 \%$ and $70 \%$ of the yield point. The strain energy density was calculated by integrating the stress versus strain curve. 


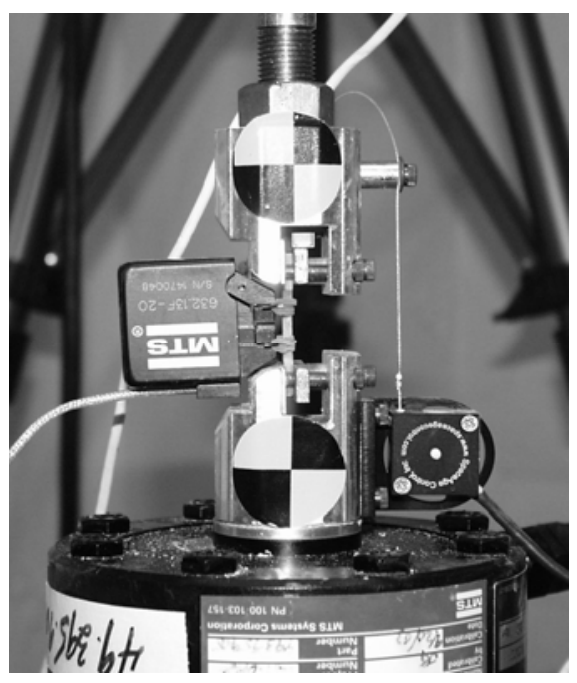

Figure 5: The rib tests utilized the extensometer as the primary strain measurement device and the potentiometer was for redundancy in case of extensometer failure.

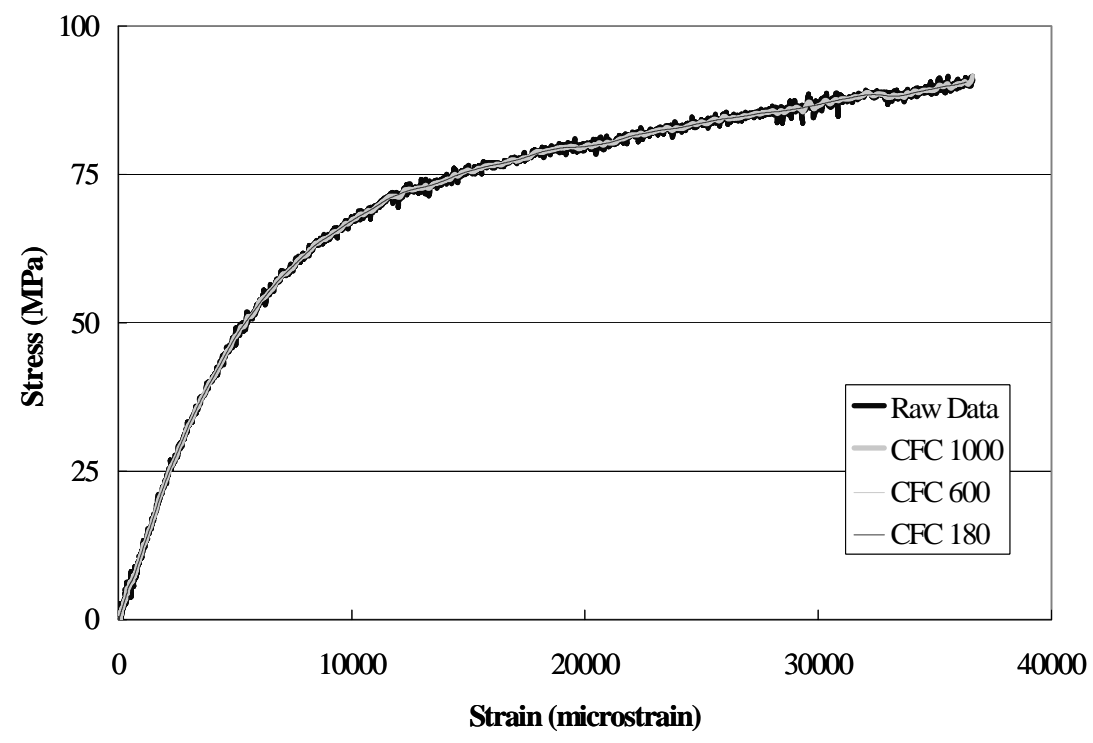

Figure 6: Example plot of raw data and different CFC filters showing the elimination of noise without affecting the signal.

\section{Percent Mineralization}

An ashing process, described below, was used to determine the percentage mineralization in each rib coupon (Yeni, 1998). The rib coupons were soaked in a saline solution overnight then blotted dry and weighed, giving the wet weight. Each specimen was 
vacuum dried at $100^{\circ} \mathrm{C}$ for 24 hours. The specimens were removed from the oven and allowed to cool at room temperature for 30 minutes before being weighed. The resulting weight was called the dry weight, and consisted of the weight of organic and inorganic materials. Specimens were then ashed in a muffle furnace at $600{ }^{\circ} \mathrm{C}$ for 24 hours, removed from the furnace and allowed to cool at room temperature for one hour. Each specimen was weighed following the cooling period, giving the ash weight. The ash weight consisted of the weight of only the inorganic materials. The percent mineralization was then calculated (Equation 1). All weight measurements were taken using an analytical scale with a resolution of $0.1 \mathrm{mg}$.

$$
\% \text { Mineralization, } \% \text { Min }=\frac{\text { Ash Weight }}{\text { Dry Weight }} \times 100
$$

\section{Statistical analysis}

Statistical analysis was performed by analyzing the data on the basis of independent variables gender, age, rib level, anatomical region, global BMD, and percent mineralization and dependent variables of ultimate stress, ultimate strain, elastic modulus, and strain energy density. The goal of the statistical analysis was to determine if there are any statistical differences in material properties with respect to gender, age, rib level, anatomical region global BMD, or percent mineralization. A mixed model was used to compare the dependant variables for all tests to the independent variables in order to determine any interaction effects. Simple Analysis of Variance (ANOVA) was used to test the data. Significance was determined by a p-value of 0.05 or less and a $\mathrm{R}^{2}$ value of 0.5 or greater. 


\section{RESULTS}

\section{Rate Comparison}

In order to validate that the strain rates for these tests were representative of an actual severe crash, the data was compared to data obtained from a dynamic chest compression test on a thorax instrumented with 47 strain gages (Duma, 2005) (Figure 7). The average of all of results, $0.5 \mathrm{strain} / \mathrm{sec}$, was the target strain rate for the current study.

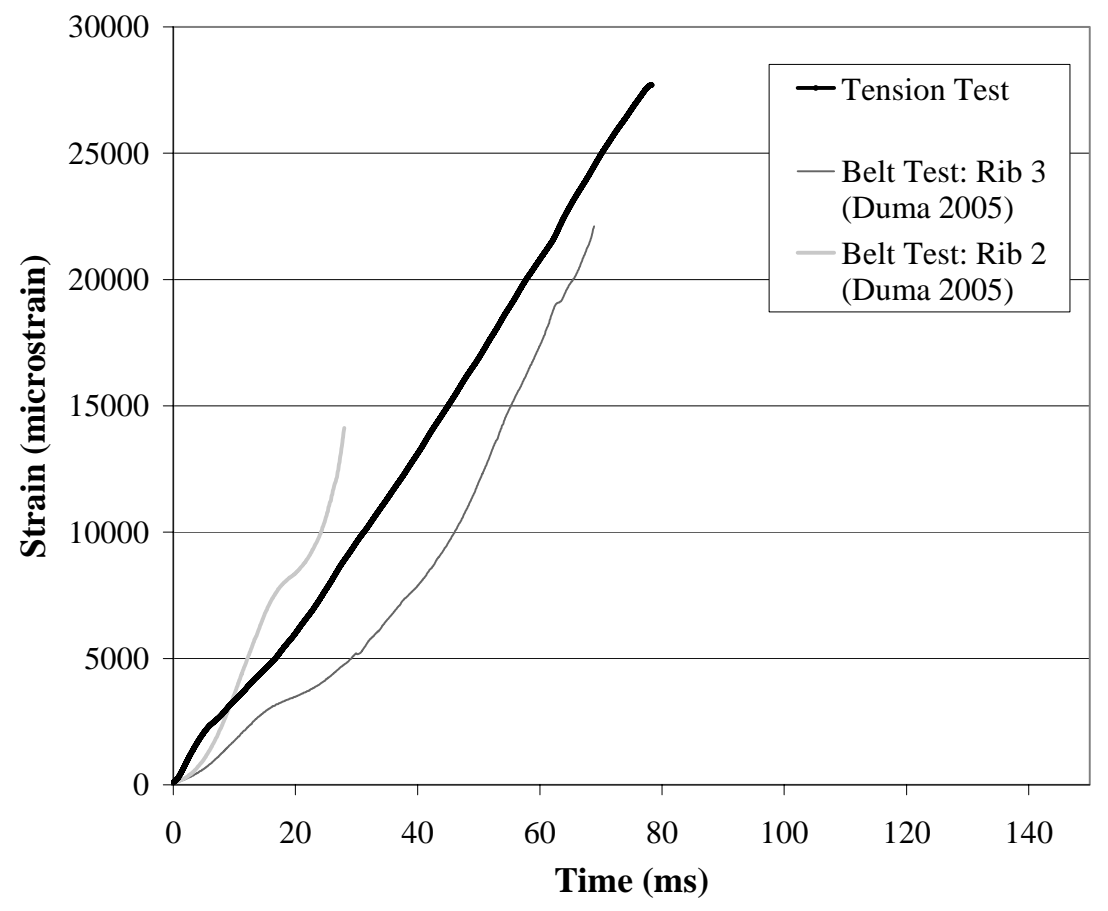

Figure 7: Strain rate comparison: dynamic chest compression (Duma, 2005) versus presented rib tension testing data. 


\section{Material Properties}

The stress versus strain plots for each cadaver as well as plots of the average elastic modulus, strain rate, ultimate stress, ultimate strain, and strain energy density with respect region, rib level, age, gender, BMD, and percent mineralization are presented in this section. Due to imperfections in the cortical bone of some specimens not all the dog bone samples broke within the $10 \mathrm{~mm}$ gage length, which is the area in which the extensometer measured the local strain. This resulted in uncertainty in the ultimate stress, ultimate strain, and strain energy density past the point of yielding for the specimens that had fractures outside the gage length. The uncertainty in the ultimate strain was due to the fact that the local strain was not directly measured outside of the gage length. However, the modulus (E) is still valid for these tests under the assumption that the coupon strains evenly up to the yield point. The test specimens that had fractures outside the grip area are designated by an asterisk $\left(^{*}\right)$ in the tables and plots presented in this paper (Appendix A; Figures 8-25). For the final analysis and averages, all data was used for the modulus (E), and only the tests that failed inside the active area were used for the ultimate stress, ultimate strain, and strain energy density values. The test results are presented in 18 figures and six tables (Figures 8 - 25; Appendix A). 


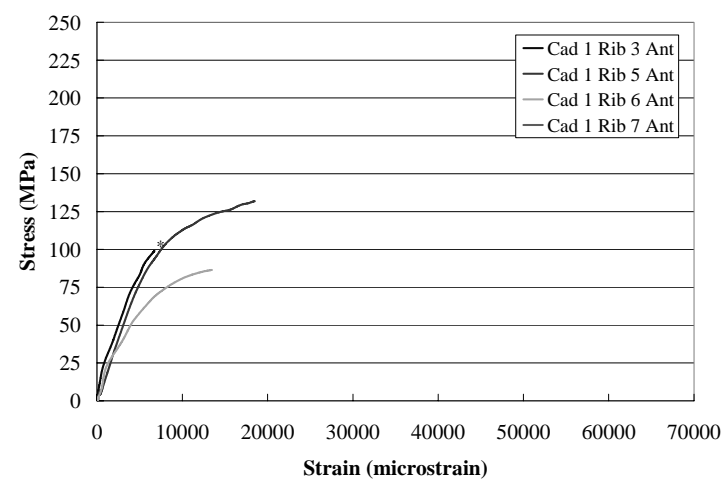

Figure 8: Cadaver 1 anterior section stress versus strain plot.

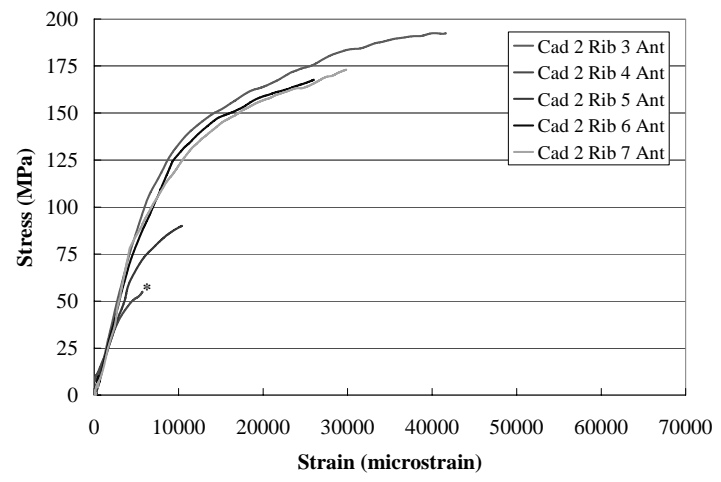

Figure 9: Cadaver 2 anterior section stress versus strain plot.

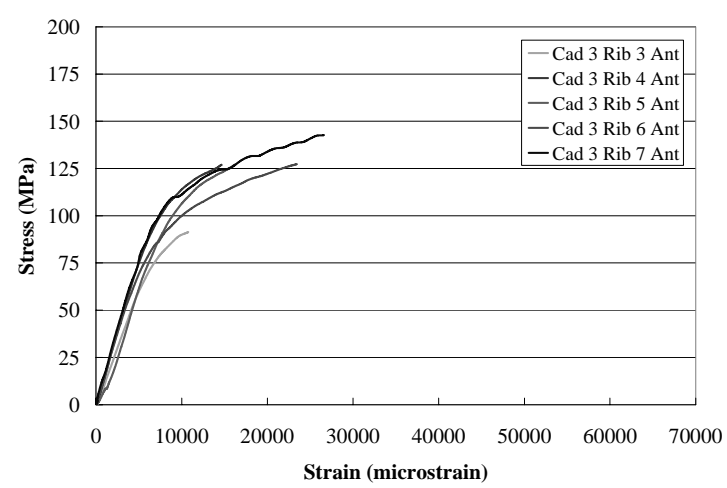

Figure 10: Cadaver 3 anterior section stress versus strain plot.

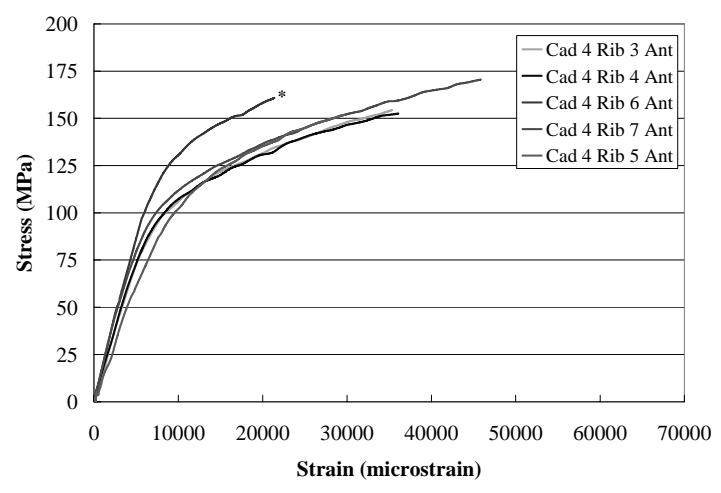

Figure 11: Cadaver 4 anterior section stress versus strain plot.

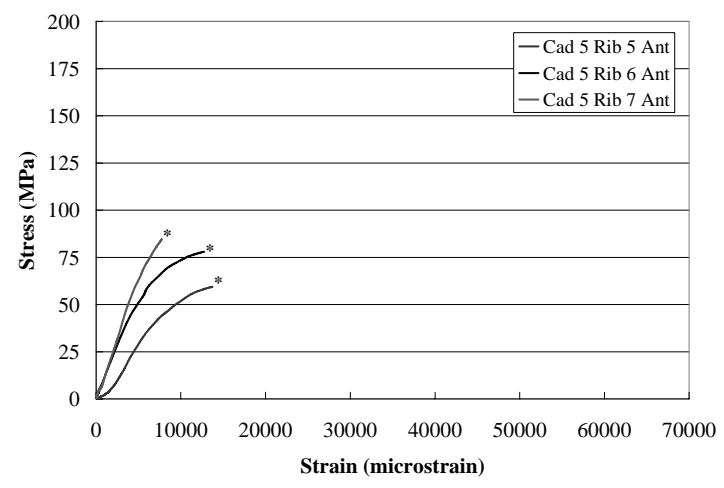

Figure 12: Cadaver 5 anterior section stress versus strain plot.

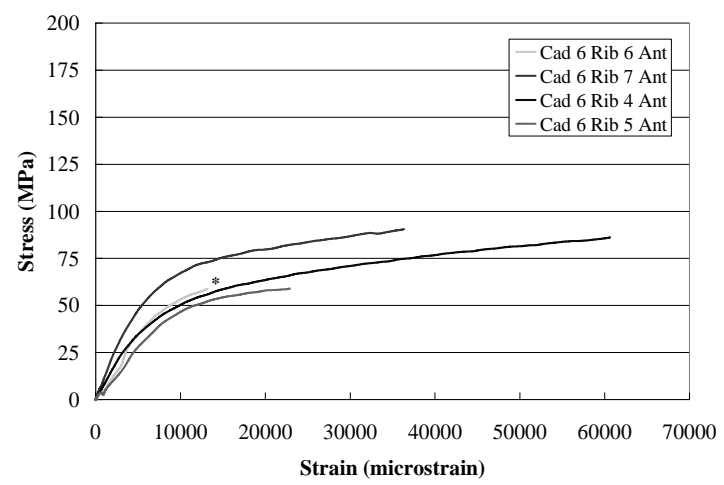

Figure 13: Cadaver 6 anterior section stress versus strain plot. 


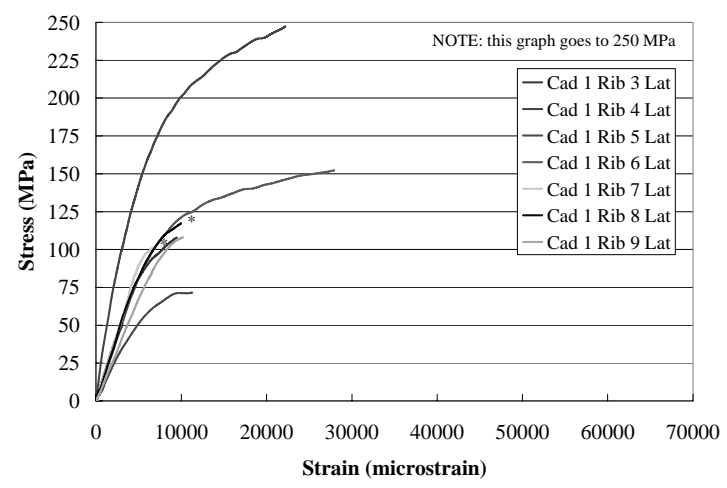

Figure 14: Cadaver 1 lateral section stress versus strain plot.

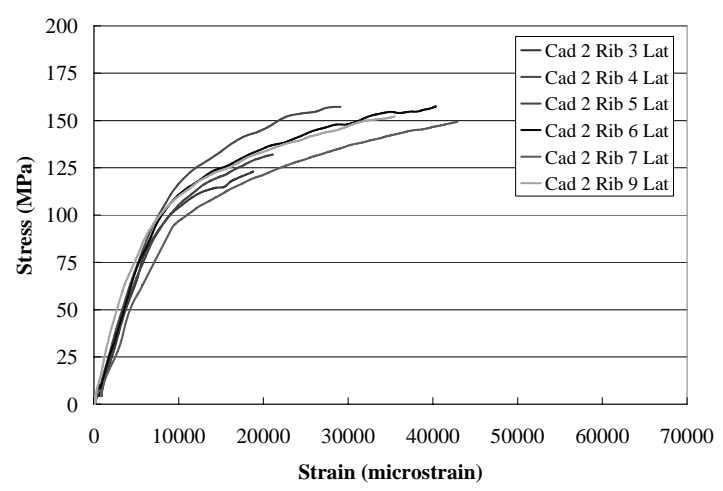

Figure 15: Cadaver 2 lateral section stress versus strain plot.

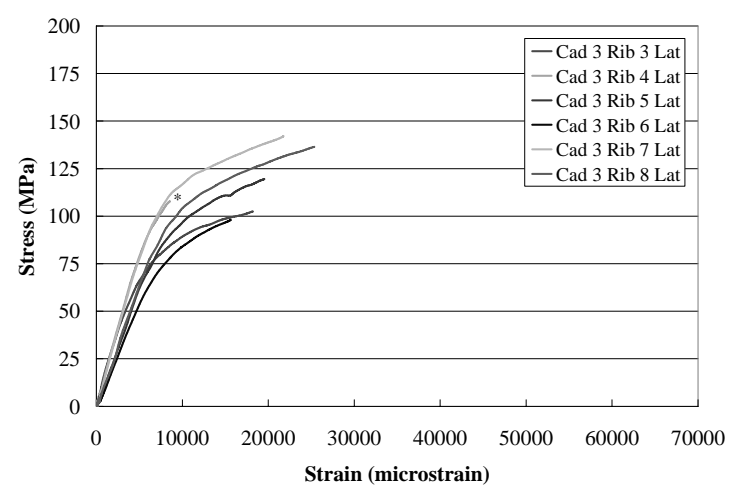

Figure 16: Cadaver 3 lateral section stress versus strain plot.

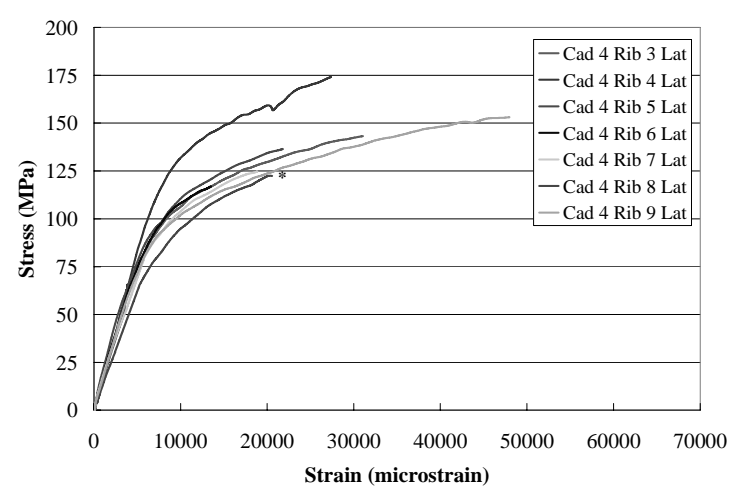

Figure 17: Cadaver 4 lateral section stress versus strain plot.

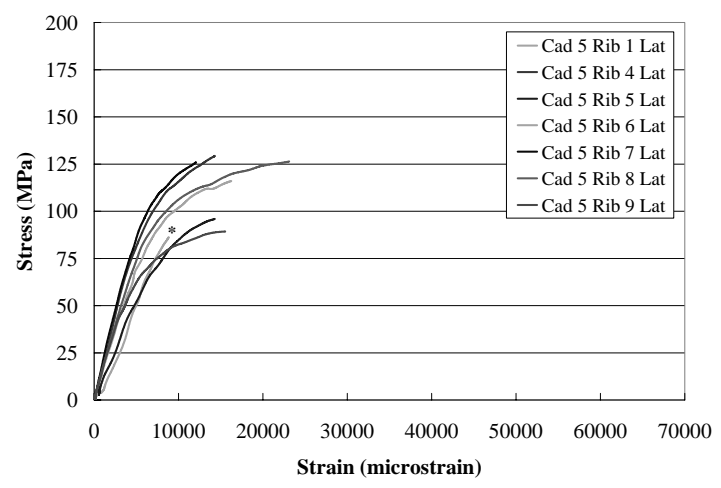

Figure 18: Cadaver 5 lateral section stress versus strain plot.

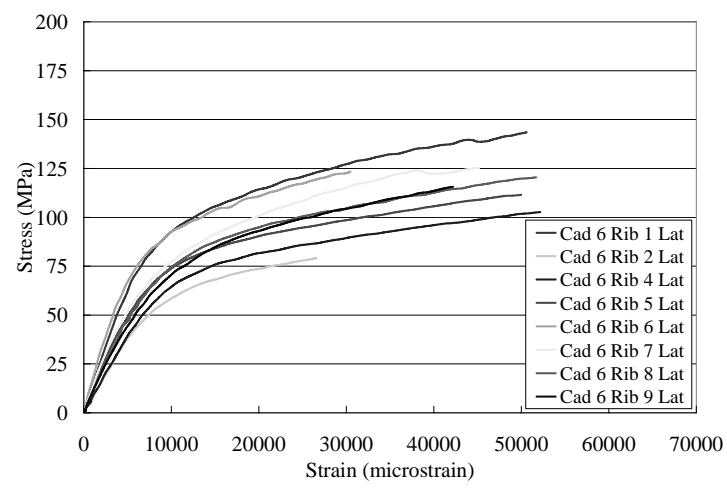

Figure 19: Cadaver 6 lateral section stress versus strain plot. 


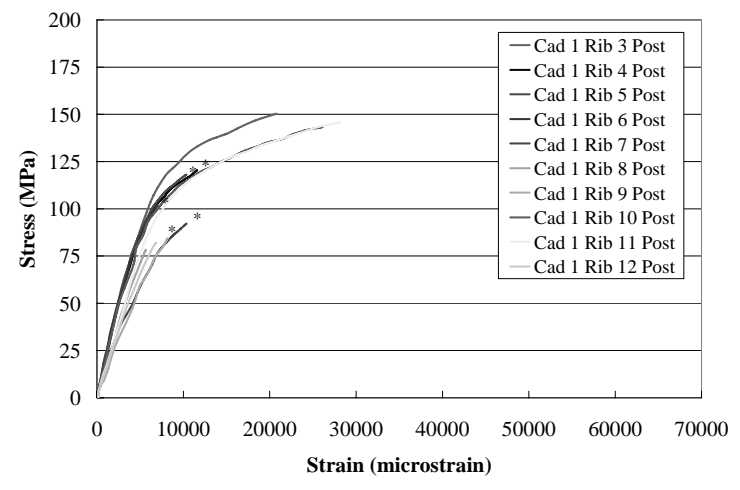

Figure 20: Cadaver 1 posterior section stress versus strain plot.

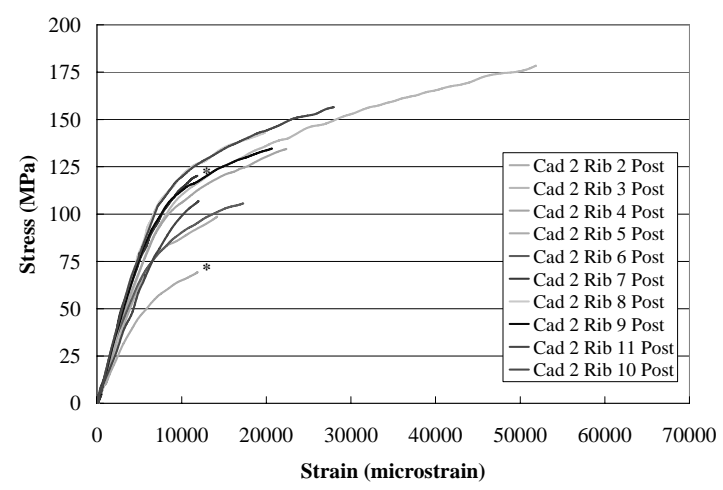

Figure 21: Cadaver 2 posterior section stress versus strain plot.

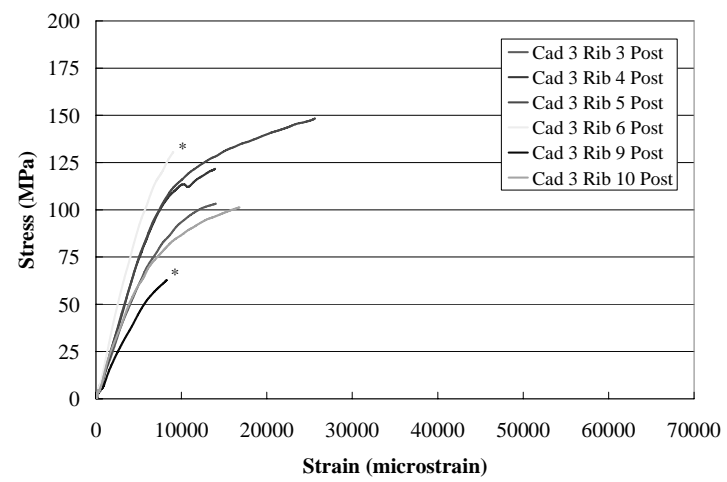

Figure 22: Cadaver 3 posterior section stress versus strain plot.

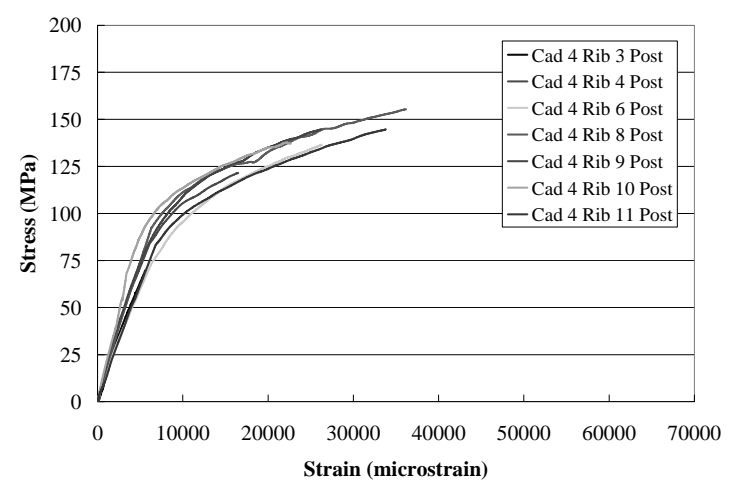

Figure 23: Cadaver 4 posterior section stress versus strain plot.

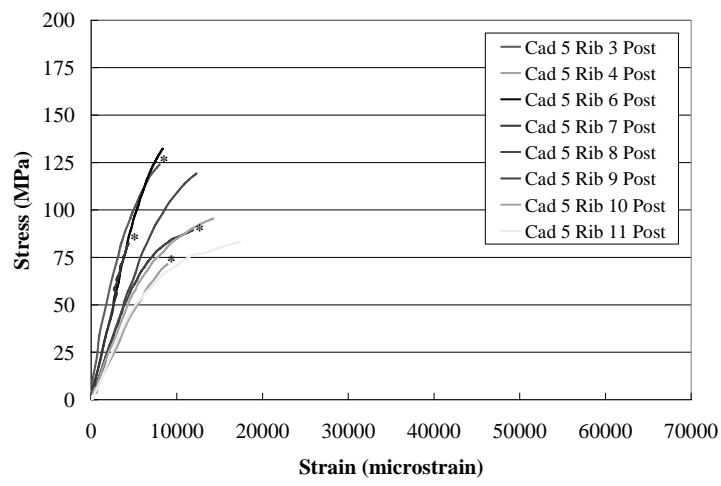

Figure 24: Cadaver 5 posterior section stress versus strain plot.

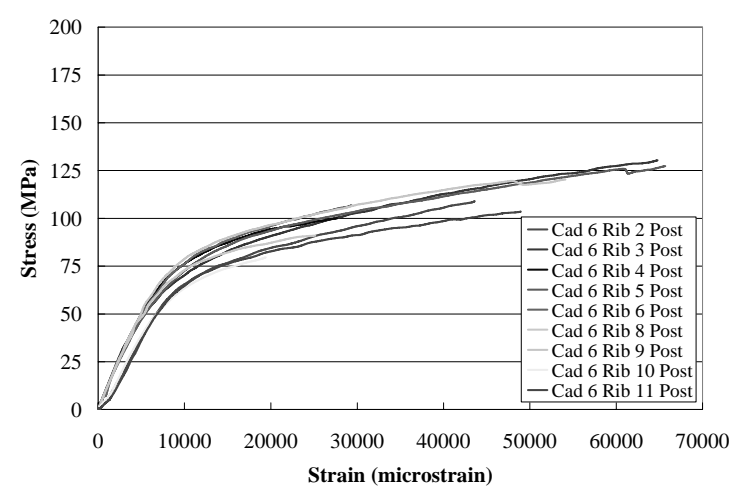

Figure 25: Cadaver 6 posterior section stress versus strain plot. 


\section{Regional Variation}

The average material properties values from each region were evaluated to determine if there were any significant differences. There were no significant differences in any material properties with respect to thoracic region (Figures 26-29).

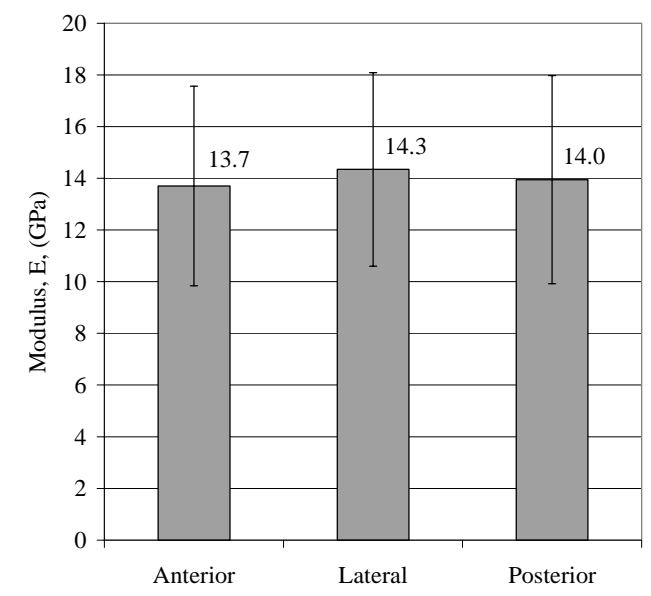

Figure 26: Average modulus, E, of anterior, lateral, and posterior regions

$$
\begin{gathered}
\text { (all tests) } \\
(\mathrm{p}=0.17) .
\end{gathered}
$$

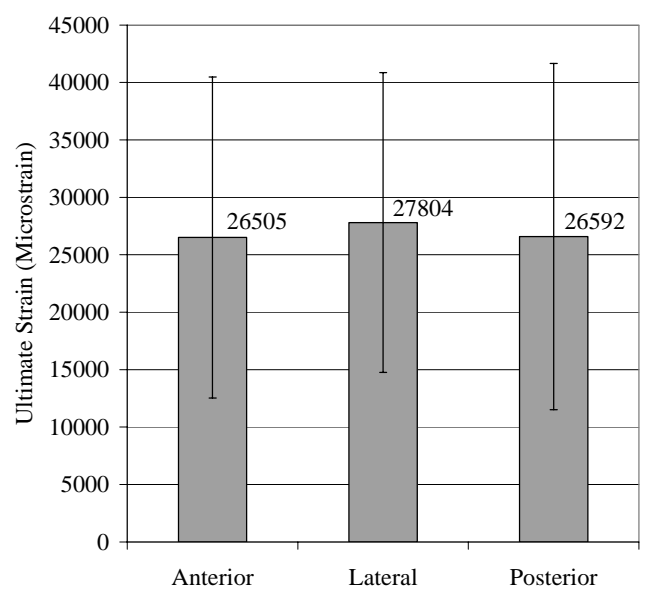

Figure 27: Average Ultimate Strain of anterior, lateral, and posterior regions

(breaks occurred in the measured region)

$$
(p=0.85) \text {. }
$$

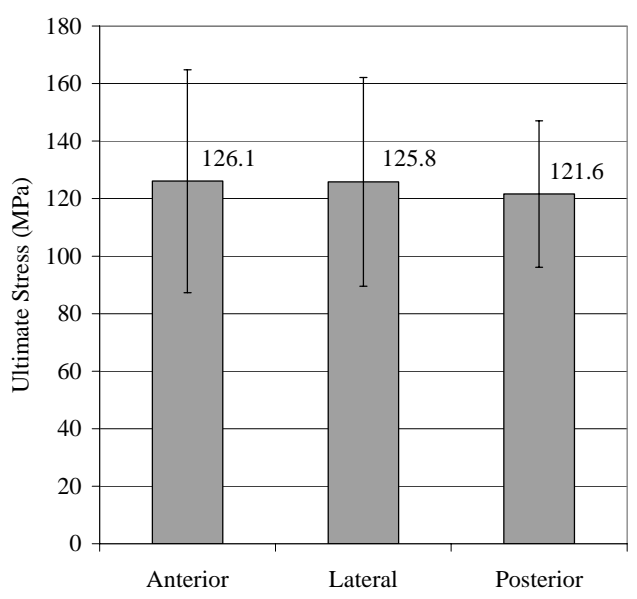

Figure 28: Average Ultimate Stress of anterior, lateral, and posterior regions

(breaks occurred in the measured region)

$$
(\mathrm{p}=0.32) \text {. }
$$

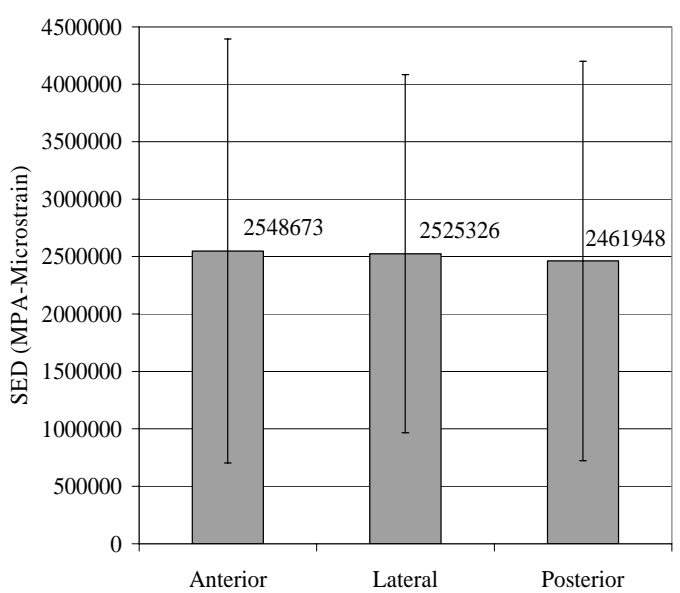

Figure 29: Average Strain Energy Density anterior, lateral, and posterior regions

(breaks occurred in the measured region)

$$
(p=0.72) \text {. }
$$




\section{Rib Level}

There was no significant difference in the material properties by rib level (Figures 30-33). Although the ultimate strain and strain energy density appear higher in rib 1 and lower in rib 12, this was due to the limited samples at those ribs, and not a characteristic of all the tests.

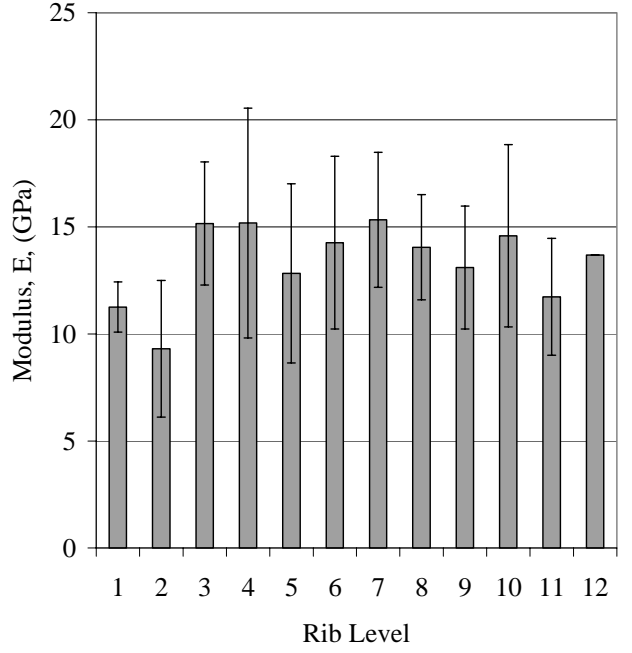

Figure 30: Average modulus, E ribs 1-12 (all tests)
$(\mathrm{p}=0.91)$

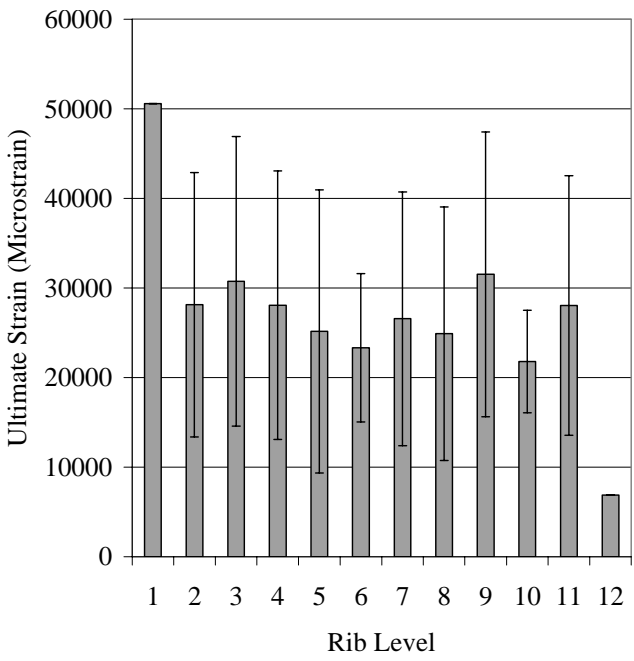

Figure 31: Average Ultimate Strain ribs $1-12$

(breaks occurred in the measured region) $(\mathrm{p}=0.27)$.

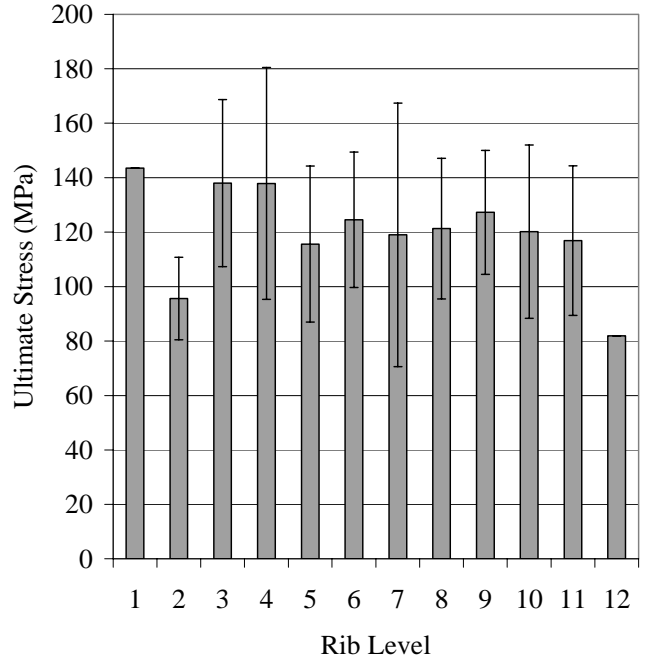

Figure 32: Average Ultimate Stress ribs 1-12 (breaks occurred in the measured region) $(\mathrm{p}=0.31)$.

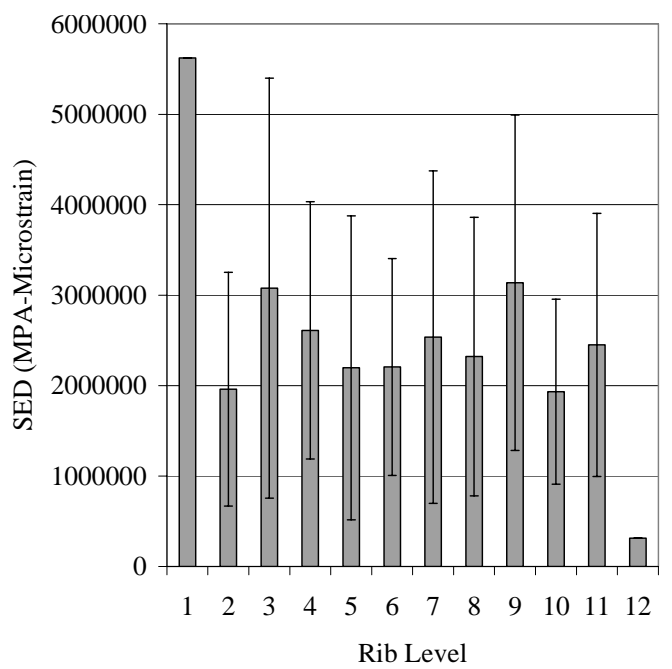

Figure 33: Average Strain Energy Density ribs $1-12$

(breaks occurred in the measured region) $(p=0.32)$. 


\section{Age Variation}

Age was a significant factor in the material properties of human rib cortical bone (Figures 34-37). The results show a significant decrease in average ultimate strain $(\mathrm{p}<0.01)$ and average strain energy density $(\mathrm{p}<0.01)$ with increasing age. The results show a significant increase in the average modulus $(\mathrm{p}<0.01)$ when all ages are considered. However, there is no significant difference in the modulus if the 18 year old cadaver is removed $(p=0.50)$.

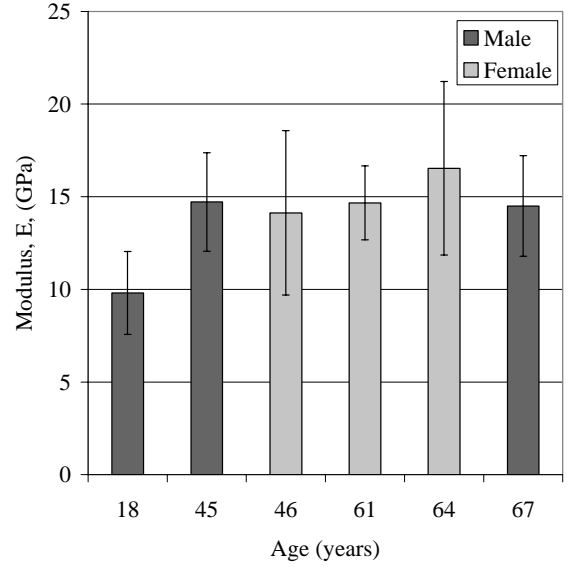

Figure 34: Average modulus, E, by age

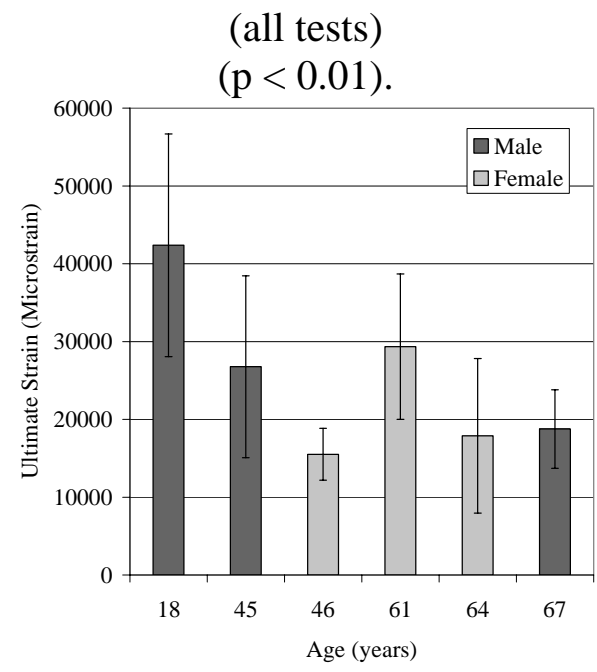

Figure 35: Average Ultimate Strain by age

(breaks occurred in measured region) $(\mathrm{p}<0.01)$.

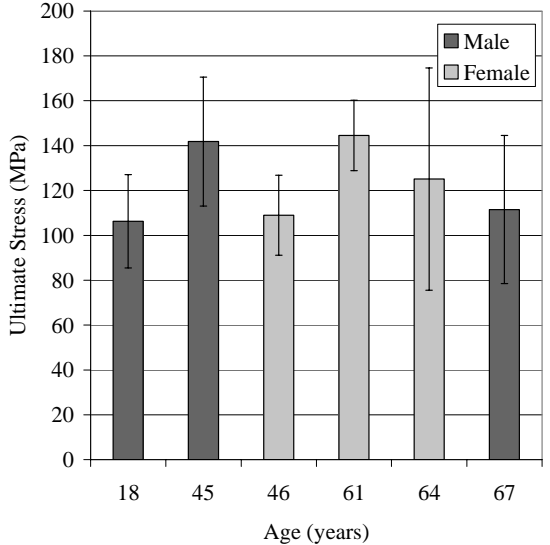

Figure 36: Average Ultimate Stress by age (breaks occurred in the measured region)

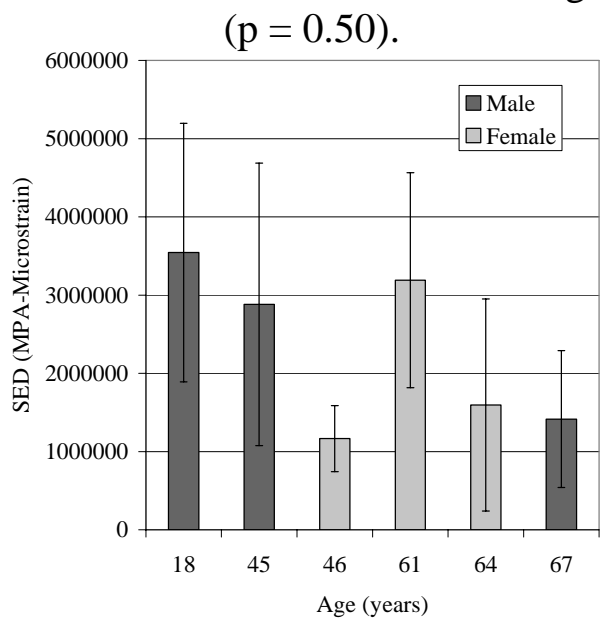

Figure 37: Average Strain Energy Density by age

(breaks occurred in the measured region) $(\mathrm{p}<0.01)$. 


\section{Gender Variation}

There were significant differences found between the male and female genders (Figures 38-41). The females had a significantly higher average elastic modulus than the males (p $<0.01)$, while the males had a significantly higher average ultimate strain $(\mathrm{p}<0.01)$. The difference in average ultimate stress for the males and the females was not found to be significant $(\mathrm{p}=0.16)$.

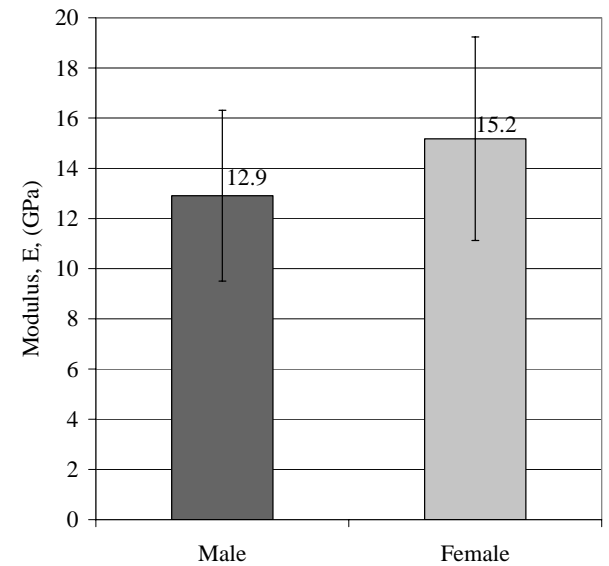

Figure 38: Average modulus, E, by gender

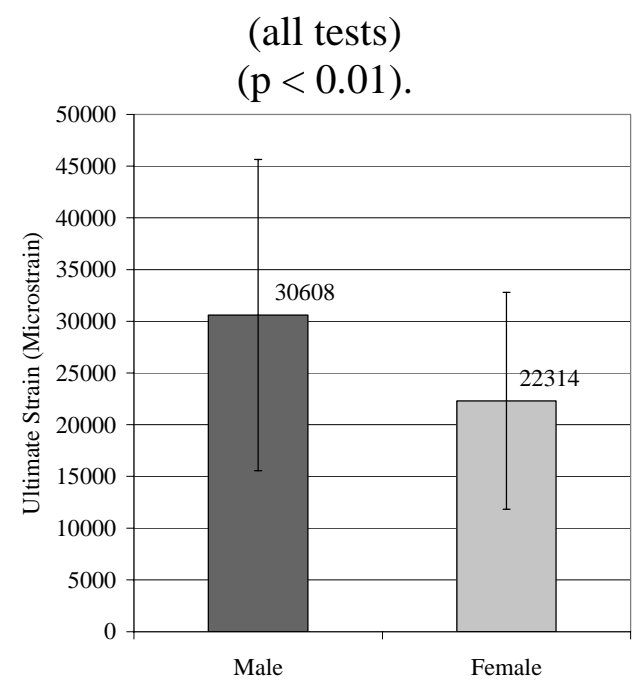

Figure 39: Average Ultimate Strain by gender

(break occurred in the measured region) $(\mathrm{p}<0.01)$.

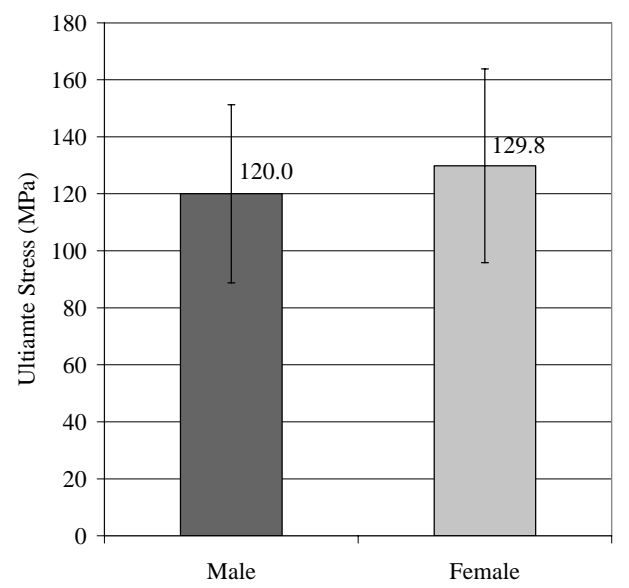

Figure 40: Average Ultimate Stress by gender

(break occurred in the measured region)

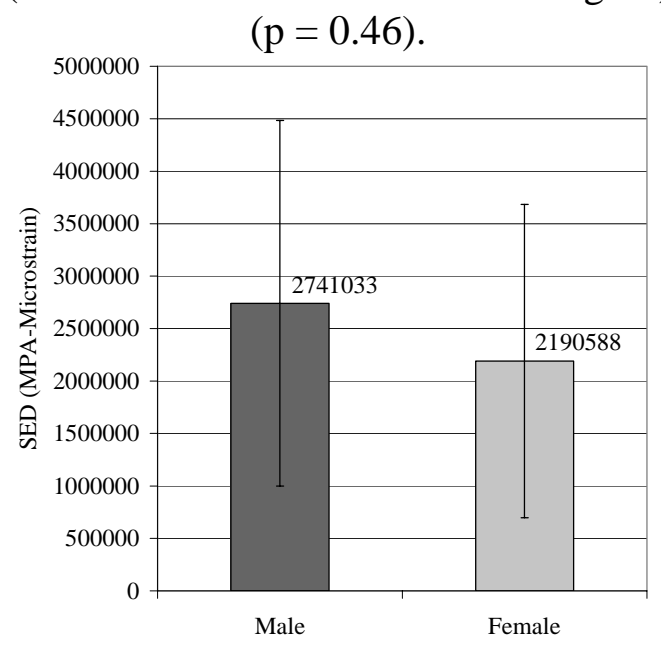

Figure 41: Average Strain Energy Density by gender

(break occurred in the measured region) $(p=0.09)$. 


\section{Global Bone Mineral Density}

Global BMD had a significant factor in the average material properties of human rib cortical bone (Figures 42-45). There was a significant decrease in the average modulus (p $<0.01)$ and a significant increase in average ultimate strain $(\mathrm{p}<0.01)$ with increasing global bone mineral density.

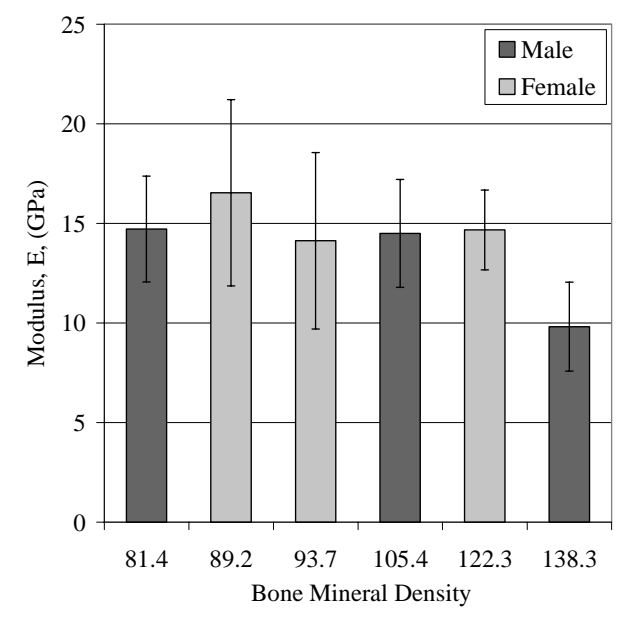

Figure 42: Average modulus, E, by BMD

\section{(all tests)}

$(\mathrm{p}<0.01)$.

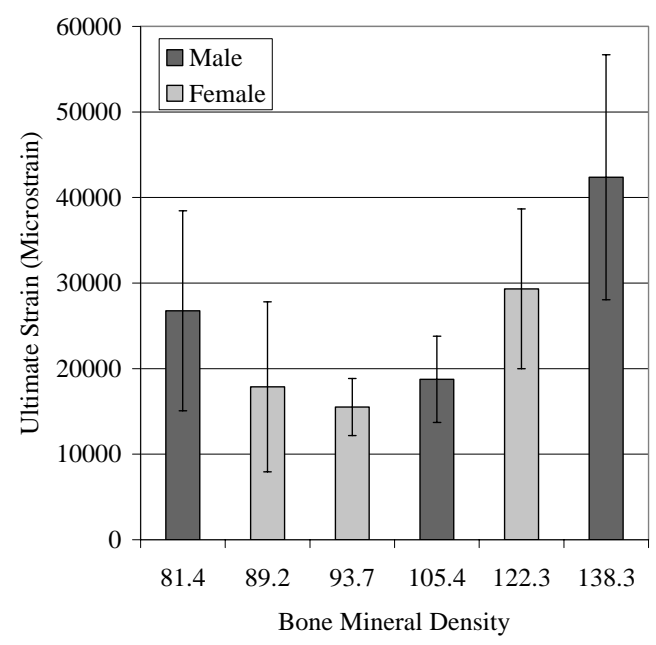

Figure 43: Average Ultimate Strain by BMD

(breaks occurred in the measured region)

$$
(\mathrm{p}<0.01) \text {. }
$$

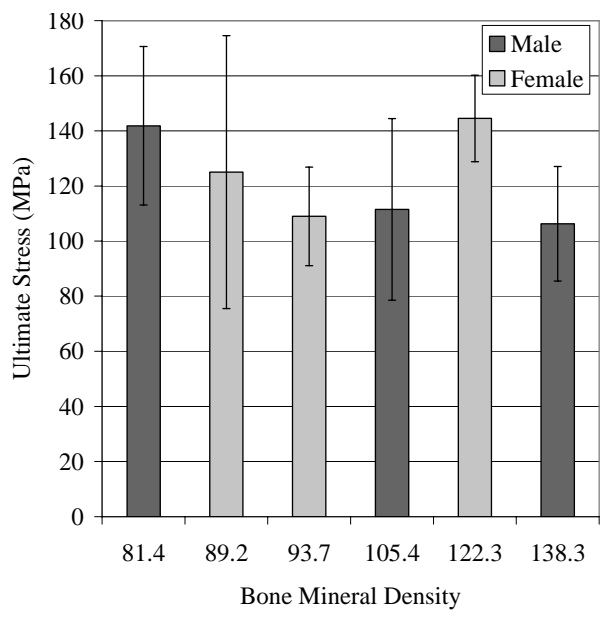

Figure 44: Average Ultimate Stress by BMD

(breaks occurred in the measured region) $(\mathrm{p}=0.50)$.

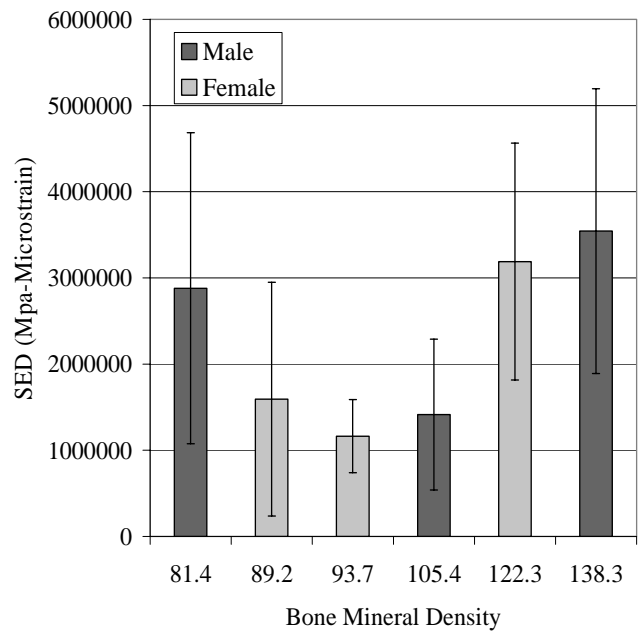

Figure 45: Average Strain Energy Density by BMD

(breaks occurred in the measured region) $(\mathrm{p}=0.50)$. 


\section{Percent Mineralization}

There was no significant difference in the material properties with respect to percent mineralization within a cadaver (Figures 46-49). In addition, there was no significant difference in percent mineralization with respect to age $(p=0.50)$, gender $(p=0.17)$, rib level $(\mathrm{p}=0.19)$, or region $(\mathrm{p}=0.68)$. Therefore, the relative concentrations of organic and inorganic materials do not account for the changes in material properties seen in this study between cadavers.

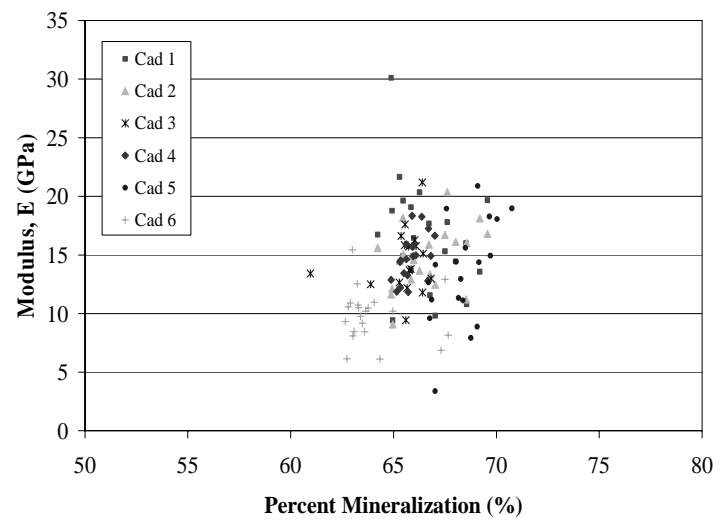

Figure 46: Average modulus, E, versus Percent Mineralization

$$
\begin{gathered}
\text { (all tests) } \\
(\mathrm{p}=0.25) .
\end{gathered}
$$

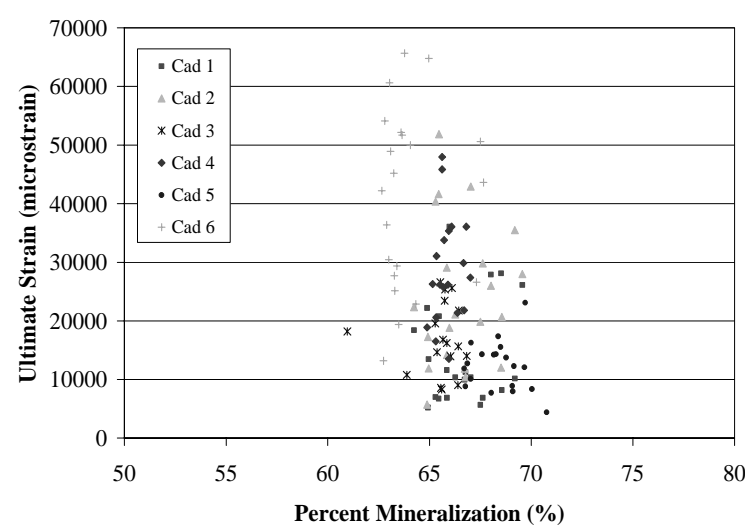

Figure 47: Average Ultimate Stress versus Percent Mineralization

(breaks occurred in the measured region)

$$
(p=0.50) \text {. }
$$

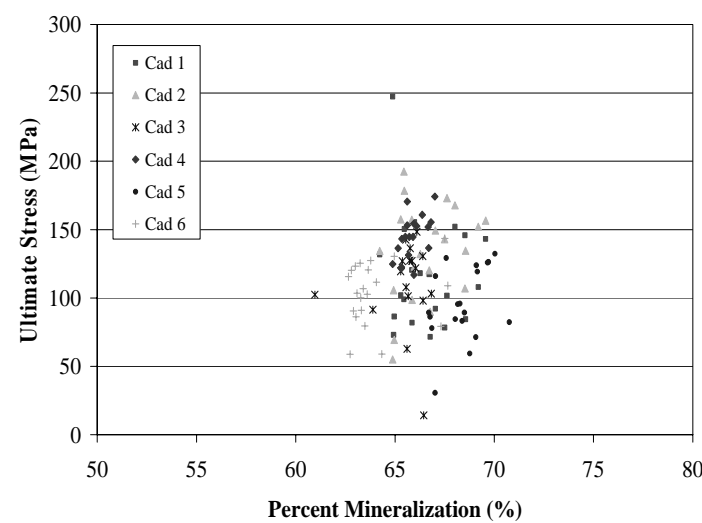

Figure 48: Average Ultimate Stress versus Percent Mineralization

(breaks occurred in the measured region) $(p=0.62)$.

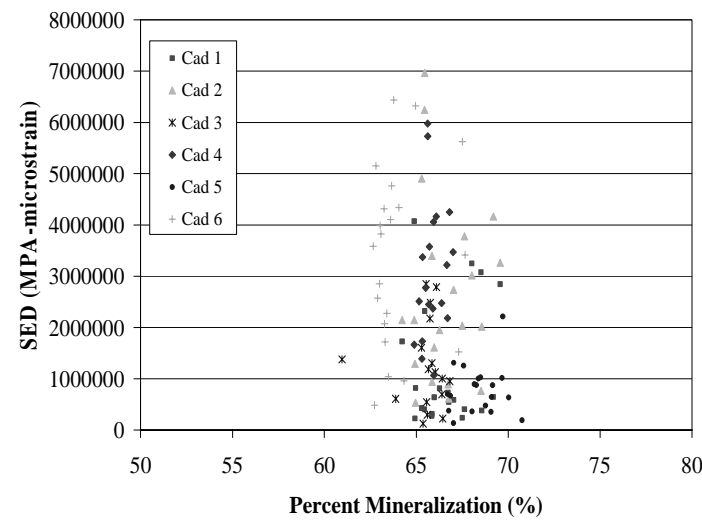

Figure 49: Average Strain Energy Density versus Percent Mineralization

(breaks occurred in the measured region)

$$
(p=0.50) \text {. }
$$




\section{DISCUSSION}

\section{Three-Point Bending versus Tension Testing}

While previous studies have investigated the biomechanical properties of human rib cortical bone, the research to date has utilized three-point bending, which has inherent limitations. The most important of these limitations is the necessity to calculate stress, strain, and modulus with linear elastic beam equations that do not take plasticity into account. As a result, the calculated stress at failure will be too high. Burstein (1972) found that linear elastic beam equations can overestimate the ultimate stress 50 to 100 percent, and suggested that the ultimate stress determined from three-point bending tests could be corrected by dividing by a factor of 1.56 . Additionally, calculating strain by impactor displacement may tend to overestimate the strain and thereby underestimate the elastic modulus due to the presence of shear (Cowin, 2001). In some three-point bending studies, strain has been measured by placing a strain gage on the tensile side of the specimen (Duma, 2005). Although this is a direct measure of strain during the test event, the measured ultimate strain may be lower than the true ultimate strain, depending on the location of the fracture relative to the strain gage (Kemper, 2005). Tension testing avoids the need to calculate material properties based on equations that assume linear elastic behavior and the subsequent correction factors needed to account for plasticity, because stress and strain can be measured directly. Therefore, tension testing provides more accurate means of determining the exact material properties of human cortical bone.

Given that these tests were performed in tension, the level of plasticity can be quantified directly. Burstein (1972) noted that bone exhibits a large amount of plasticity, provided 
that extreme care is taken during specimen preparation and testing to maintain specimen hydration. The results from the current study are consistent with this finding, in that they show that there is a large contribution from plasticity. For all cadavers, the plastic region of the stress versus strain curves was substantial and contributed to approximately $60 \%$ of the overall response, and up to $80 \%$ for the 18 year old cadaver. Furthermore, although the average ultimate strain for all cadavers in this study was $2.69 \%$ strain, the average ultimate strains for the 18 year old cadaver was $4.3 \%$ strain. However, the ultimate strains for the 18 year old cadaver were as high as $6.5 \%$ strain, which is significantly larger than previously reported ultimate strain values of $3.0 \%$ strain to $4.9 \%$ strain (Burstein, 1976; McCalden, 1993). The large degree of plasticity shown by the 18 year old cadaver could be a result of many age related bone changes, which are discussed in later sections.

\section{Regional Variation}

The overall structural response of whole bone sections subjected to three-point bending is effected by both geometry and material properties. Therefore, variations in this structural response between specimens can be a result of changes in the bone geometry, changes in the bone material properties, or changes in both. Cormier (2005) reported that whole rib sections subjected to three-point bending demonstrated regional variation in the overall structural response with the anterior lower than the lateral and posterior values. In addition, Cormier (2005) showed that there are statistically significant geometry changes by anatomical region in that the distance from the neutral axis $(p=0.01)$ and the radius of gyration $(\mathrm{p}=0.05)$ vary significantly by anatomical region. Specifically, the anterior ribs

are thinner, and this results in lower structural response versus the lateral and posterior rib sections. 
In contrast to the findings of Stitzel (2003), the results of the current study indicate that the material properties of human rib cortical bone, specifically the modulus and ultimate stress, do not vary significantly by thoracic region or rib level. Although the dynamic three-point bending tests on small rectangular cortical bone coupons conducted by Stitzel (2003) avoid the geometric issues associated with whole rib testing, there are two issues that introduce uncertainty in the calculated material properties reported by Stitzel (2003). First, there are the inherent limitations associated with calculating material properties form three-point bending. Specifically, the possibility of overestimating the strain and thereby underestimating the elastic modulus due to the presence of shear, and the overestimation of ultimate stress due to the fact that elastic beam equations that do not take plasticity into account. Although the calculated ultimate stress reported by Stitzel (2003) was dividing by a correction factor to account for plasticity, this method, however, only provides an approximation for the true ultimate stress. The correction factor used was an average of the difference in ultimate stress from tension testing and calculated ultimate stress from three-point bending performed by Burstein (1972). The second overall limitation was that the specimens were very thin for three-point bending and the specimen thickness correlated similarly with the trends seen with the regional variation of the material properties. For example, the average thickness of the anterior specimens, $0.49 \pm 0.10 \mathrm{~mm}$, was significantly lower than the average thickness of the lateral specimens, $0.57 \pm 0.12 \mathrm{~mm}$ (p $<0.01)$, and posterior specimens, $0.57 \pm 0.12 \mathrm{~mm}(\mathrm{p}<0.01)$. This was the same trend seen with the significantly lower elastic modulus for the anterior specimens compared to the lateral and posterior specimens. It is suggested that the continuum assumption for three- 
point bending equations may no longer be valid for such small specimen thicknesses, and that this error is augmented with the smaller thickness specimens from the anterior regions. Given that an osteon is approximately $0.2 \mathrm{~mm}$ in diameter, the three-point bending tests on the anterior specimens put one-half of the coupon in tension or the equivalent of approximately one osteon.

In summary, when the results of the current study are considered in conjunction with the previous three-point bending tests on whole ribs and rib coupons, there is significant regional variation in the overall structural response of the human rib cage. This variation appears to be primarily a result of significant changes in the local geometry of each rib while the material properties are relatively constant within an individual. Furthermore, there are significant differences in the material properties of the human rib cage between individuals as is discussed in the next section.

\section{Variation between Cadavers}

In the current study, age was determined to be a significant factor in some but not all material properties of human rib cortical bone. In particular, the ultimate strain $(\mathrm{p}<0.01)$ and strain energy density $(\mathrm{p}<0.01)$ of human rib cortical bone were found to decrease significantly with age. The results also show a significant increase in the average modulus ( $p<0.01)$ with increasing age, when all ages are considered. However, there is no correlation between the modulus and age if the 18 year old cadaver is removed. In addition, the yield point was found to be independent of occupant age, indicating the beginning of the plastic region as it was consistently between $0.6 \%$ strain and $0.8 \%$ strain. 
On the other hand, the plastic region of the stress versus strain curve decreased significantly with increasing age $(\mathrm{p}<0.01)$ (Figure 50$)$. This indicates that the largest changing factor for age effects on bone material properties is the amount of plasticity while the yield strain is relatively constant.

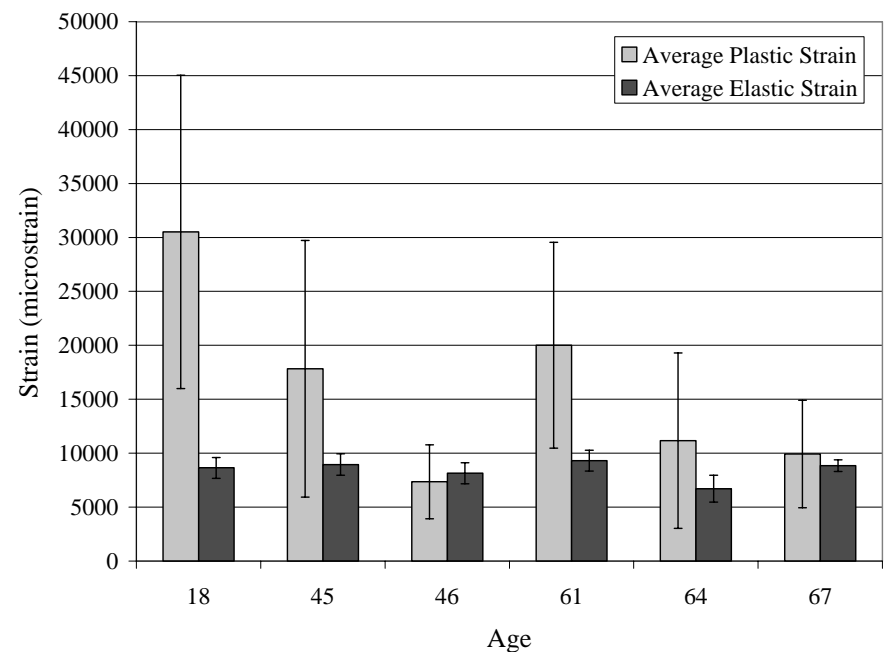

Figure 50: Average elastic and plastic strain versus cadaver age.

The age correlations with respect to ultimate strain, strain energy density, and modulus found in this study are consistent with the findings of both McCalden (1993) and Burstein (1976). Burstein (1976) reported that the ultimate strain and energy of tibia cortical decrease significantly with age. However, Burstein (1976) performed matched tests on the femoral cortical bone, and reported that ultimate stress, ultimate strain, elastic modulus, and energy all significantly decrease with age. McCalden (1993) reported the ultimate strain and energy of the femur significantly decrease with age. In addition, McCalden (1993) reported that the energy in the elastic region did not change with age, while the energy in the plastic region significantly decreased with increasing age $(p<0.01)$. Lindahl (1967) reported that the ultimate stress of both femur and humerus cortical bone decreased with age, along with the ultimate strain. Burstein (1976) attributed the differences between the matched tibia and femur specimens to differences at the tissue and structure or organ 
level, which vary based on the loading conditions the different bones are subjected to. McCalden (1993) performed a histological study, and found that the amount of haversian bone as well as osteon size increase with age. When the findings of all these studies are considered in conjunction with one another, the overall conclusion is that the ultimate strain and energy of cortical bone significantly decrease with age regardless of the bone it was obtained from, while the relationship of ultimate stress with respect to age varies between individual bones due to tissue and or structure differences.

Gender was also found to be a significant factor in the material properties of human rib cortical bone. Females were found to have more brittle rib cortical bone than males, shown by a larger average modulus ( $\mathrm{p}<0.01)$, a lower average peak strain $(\mathrm{p}<0.01)$, and a lower strain energy density $(p=0.08)$. These findings contradict the findings of some previous researchers that found no significant differences with respect to gender in material properties obtained from coupon testing (Lindahl, 1967; Yeni, 1998; Stitzel, 2003). However, Lindahl (1967) and Yeni (1998) had a significantly larger number of cadavers from which specimens were taken. In addition, the age of the female subjects in this study were significantly older than the males $(\mathrm{p}<0.01)$, which may explain the differences in material properties. In other words, the 18 year old male data influences the significant changes between genders.

\section{Bone Mineral Density and Percent Mineralization}

BMD represents the relative volume of bone versus porous space, while factoring in the extent of mineral content. The results of this study showed BMD is a significant factor in 
the material properties of human rib cortical bone. There was a significant decrease in the average modulus ( $\mathrm{p}<0.01)$, and a significant increase in average ultimate strain $(\mathrm{p}<0.01)$ with increasing BMD. There was no significant difference in ultimate stress with respect to BMD. These results seem to contradict those of previous researchers, who have found that the ultimate stress and modulus increase significantly with apparent wet and dry density (Keller, 1994; Carter, 1976; Martin, 1989; McCalden, 1993; Muellar, 1966; Schaffler, 1988). However, wet and dry densities are obtained from each individual specimen, while BMD in this study was determined from an X-ray of the left hand. Therefore, the BMD measurement in this study only provides an indication of overall bone strength and does not account for local changes in bone density or composition.

There have been a few authors that have reported correlations in material properties to changes in the relative concentrations of collagen and mineral salts, for example percent mineralization. Schaffler and Burr (1988) reported that the modulus increased with increasing percent mineralization. Martin (1989) reported the mineralization is inversely correlated to strength. However, this correlation was both weak and non-linear. Currey (1988) found that calcium content, which is closely related to percent mineralization, increases nonlinearly with increasing modulus. In contrast to these findings, the results of the current study show that there were no correlations found in the percent mineralization with respect to material properties, rib region, rib level, age, or gender. These findings are consistent with the findings of numerous previous authors (McCalden, 1993; Muellar, 1966; Schaffler, 1988). Therefore, the relative concentrations of organic and inorganic materials do not account for the changes in material properties seen in this study. 
Percent mineralization, however, is only part of the overall BMD and does not take porosity into account, which has been shown to have a significant influence on material properties (Currey, 1988; Schaffler, 1988; McCalden, 1993). In addition, wet and dry apparent densities of cortical bone, which are functions of both mineralization and porosity, have been shown to increase with increasing mechanical properties (Carter, 1976; Keller, 1994; Martin, 1989; McCalden, 1993; Muellar, 1966; Schaffler, 1986). Based on these findings, the composition of cortical bone remains fairly constant both within and between individuals and the porosity, for example the amount of bone present, changes with respect to each individual.

To investigate this further, data from studies involving bone biomechanics published by Hardy (1997) and Kennedy (2004) were analyzed along with the results from the current study. In order to compare the variation of cross-sectional area, BMD, and percent mineralization for each study the data was normalized by its corresponding maximum value for a particular study. Thus, the BMD and percent mineralization data from the current study was normalized with the maximum BMD and mineralization value from this study. The same process was repeated for the data from Hardy (1997) and Kennedy (2004). Average and standard deviation values were calculated for each set of normalized data. The results are shown with the horizontal lines representing the average value for each set of data, for example the cross-sectional area, BMD, and percent mineralization, from a particular study (Figure 51). The shaded bars extending above and below each average value correspond to the standard deviation for a specific set of data 


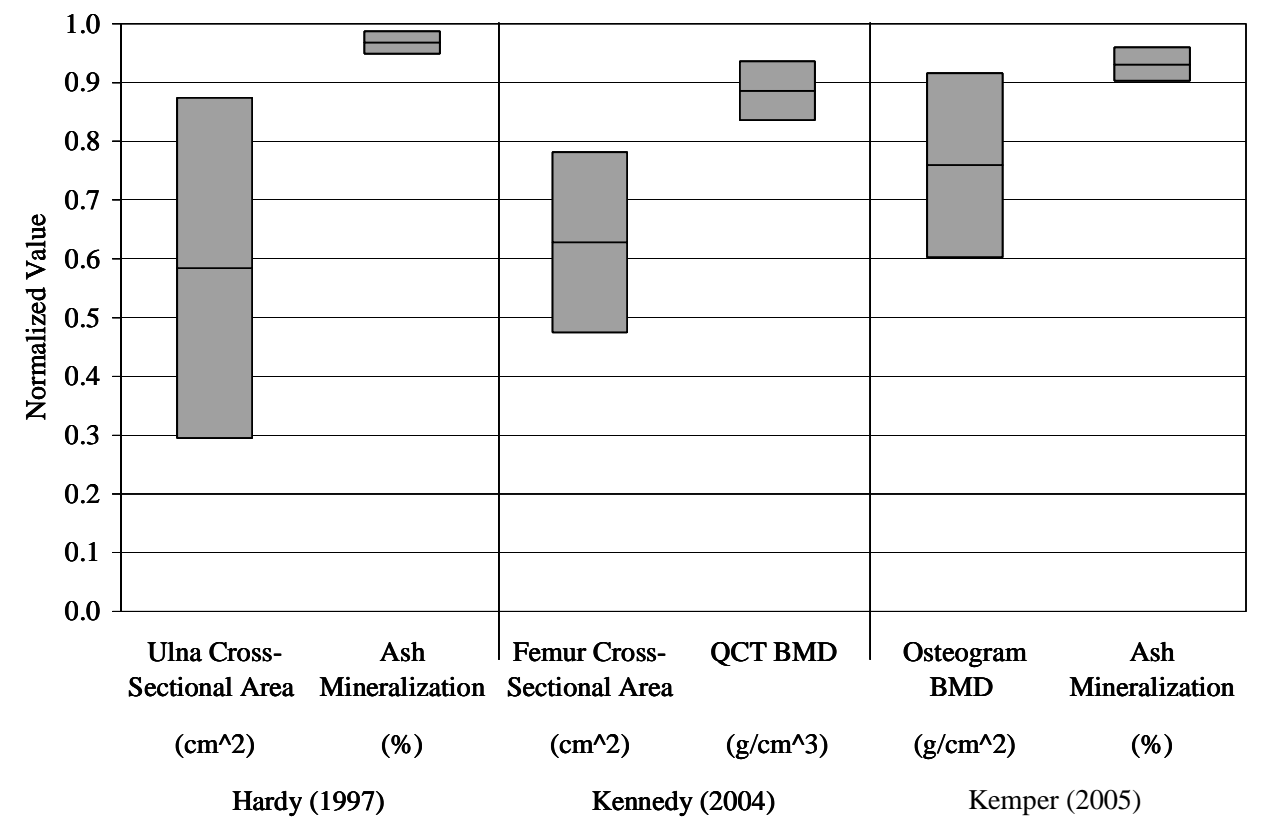

Figure 51: Normalized average and standard deviations of cross-sectional area, BMD, and percent mineralization for three studies.

Overall, it was found that there was a greater variation in cross-sectional area compared to percent mineralization with normalized standard deviation values ranging from 0.15-0.29 and 0.02-0.03, respectively. The large variation of cross-sectional area values versus the small variation of percent mineralization values may indicate that the amount of bone present changes with age or gender whereas the actual mineral content remains fairly constant. This conclusion is consistent with the findings of McCalden (1993), Muellar (1966), and Schaffler (1986).

\section{CONCLUSIONS}

The dynamic material properties of human rib cortical bone were determined from 117 tension coupons obtained from six cadavers of various ages without the confounding effects of geometry or linear elastic beam theory assumptions associated with three-point 
bending. The overall average of all cadaver data gives an elastic modulus of $13.9 \mathrm{GPa}$ a yield stress of 93.9 $\mathrm{MPa}$, a yield strain of $0.88 \%$ an ultimate stress of $124.2 \mathrm{MPa}$, an ultimate strain of $2.7 \%$, and a strain energy density of 250.1 MPa-strain. In addition, the results from the current study show that there is a large contribution from plasticity that is highly age dependent. For all cadavers, the plastic region of the stress versus strain curves was substantial and, on average, contributed to $60 \%$ of the overall response, and in some cases over $80 \%$ for the youngest specimens. When the results of the current study are considered in conjunction with the previous three-point bending tests on whole ribs and rib coupons, the overall conclusion is that there is significant regional variation in the structural response of the human rib cage and that this variation appears to be primarily a result of significant changes in the local geometry of each rib while the material properties are constant within an individual. Furthermore, there can be significant differences in the material properties of the human rib cage between individuals due to age and porosity effects. Therefore, it is suggested that the most accurate thoracic model should use varying geometry from anterior, lateral and posterior sections, with constant material properties as defined from the tensile coupons in this paper for the targeted age and gender group for which the model is designed. 


\section{REFERENCES}

ASTM Standard E 1012-99, ASTM (2004). Standard practice for verification of specimen alignment. American Society of Testing and Materials, Philadelphia, PA.

ASTM Standard E 8M-01, ASTM (2004). Standard test methods for tensile testing of metallic materials [Metric]. American Society of Testing and Materials, Philadelphia, PA.

ASTM Standard D 5026-01, ASTM (2004). Standard test methods for plastics: dynamic mechanical properties: in tension. American Society of Testing and Materials, Philadelphia, PA.

Burstein, A.H., Reilly D.T., and Victor, H.F. (1972). The ultimate properties of bone tissue: the effect of yielding. J. Biomechanics. 5, 35-44.

Burstein, A.H., Reilly D.T., and Martens M. (1976). Aging of bone tissue: mechanical properties. Journal of Bone and Joint Surgery. 58-A(1):82-86.

Carter, D.R., and Haynes, W.C. (1976). The compressive behavior of bone as a two-phase porous structure. J. of Bone and Joint Surgery. 59-A, 954- 962.

Cavanaugh, J. M. (1993). The biomechanics of thoracic trauma. In Accidental Injury Biomechanics and Prevention, ed A. M. Nahum and J. W. Melvin, 362-390. SpringerVerlag, New York.

Cormier, J.M., Stitizel, J.D., Duma, S.M., and Matsuoka, F. (2005). Regional variation in the structural response and geometrical properties of human ribs. Proc. 49th Association for the Advancement Automotive Conference, Boston, MA.

Cowin, S.C. (2001). Bone Mechanics Handbook. CRC Press, Boca Raton, FL.

Crandall, J.R., Bass, C.R., Pilkey, W.D., Miller, H.J., Sikorski, J., Wilkins, M. (1997). Thoracic response and injury with belt, driver side airbag and force limited belt restraint systems. International Journal of Crashworthiness, 2(1): 119-132.

Cromack, J.R., and Ziper, H.H. (1975) Three-point belt induced injuries: a comparison between laboratory surrogates and real world accident victoms. Stapp Car Crash Journal 19: 1-22. SAE 751141.

Crowninshield, R., and Pope M. (1974). The response of compact bone in tension at various strain rates. Annals of Biomedical Engineering. 2, 217-225.

Currey, J.D. (1959). Difference in tensile strength of bone of different histological types. $J$. Anat (London). 93, 87-95.

Curey, J.D. (1975). The effects of strain rate, reconstruction, and mineral content on some material properties of bone. J. Biomechanics. 8, 81-86. 
Currey, J.D., and BREAR, K. (1974). Tensile yield in bone. Calc. Tiss. Res. 15, 173-79.

Currey, J.D. (1988). The effects of porosity and mineral content on young's modulus of elasticity of compact bone. J. Biomechanics. 21, 131-139.

Dempster, W.T., and Lippicoat R.T. (1952). Compact bone as a non-isotropic material. Amer. J. Anat. 91, 331-362.

Dempster, W.T., and Coleman, R.F. (1961). Tensile strength of bone along and across the grain. J. Appl. Physiol. 16, 355-360.

Duma, S. M., Stitzel, J.D., Kemper, A.R., McNally, C., Kennedy, E.A., and Matsuoka, F. (2005). Non-censored rib fracture data from dynamic belt loading tests on the human cadaver thorax. Proc. $19^{\text {th }}$ International Technical Conference on the Enhanced Safety of Vehicles. NHTSA, Washington, D.C.

Elhagediab, A.M., and Rouhana, S.W. (1998). Patterns of abdominal injury in frontal automotive crashes. Proc. $16^{\text {th }}$ International Technical Conference on the Enhanced Safety of Vehicles: 327-337, NHTSA, Washington, D.C.

Evans, F. G., and Lebrow M. (1951). Regional differences in some of the physical properties of the human Femur. J. Appl. Physiol. 3, 563-572.

Evans, F. G., and Bang S. (1956). Differences and relationships between the physical properties and microscopic structure of human femoral, tibial, and fibular cortical bone. AM. J. ANAT. 120, 79-88.

Granik, G., and Stein, I. (1973) Human ribs: static testing as a promising medical application. J. of Biomechanics. 8: 237-240.

Hardy, W.N., Lawrence, W.S., Reed, M.P., and Ricci, L.L.(1997). Biomechanical investigation of airbag-induced upper-extremity injuries. Stapp Car Crash Journal 39: 122. SAE 973325.

Kallieris, D., Zerial, P.D., Rizzetti, A., and Mattern, R. (1998) Prediction of thoracic injuries in frontal collisions. Proc. 18th International Technical Conference on the Enhanced Safety of Vehicles: 1550-1563.

Keller, T.S. (1994). Predicting to compressive mechanical behavior of bone. J. Biomechanics. 27(9), 1159-1168.

Kemper, A.R., Stitzel, J. D. , Gabler, H.C., Duma , S. M., Matsuoka, F. (2005). Biomechanical response of the human clavicle: the effects of loading direction on failure 
bending properties. Proc. 49th Association for the Advancement Automotive Conference, Boston, MA.

Kennedy, E.A., Hurst, W.J, Stitzel, J.D., Cormier, J.M., Hansen, G.A., Smith, E.P., and Duma, S.M. (2004). Lateral and posterior dynamic bending of the mid-shaft femur: fracture risk curves for the adult population. Proc. $46^{\text {th }}$ Stapp Car Crash Conference. 2751. Society of Automotive Engineers, Warrendale, PA.

Lindahl, O., and Lindren, G.H. (1967). Cortical bone in man. Acta. Orthop. Scandinav. 38, 141-147.

Martin, R.B., Ishida, J. (1989). The relative effects of collagen fiber orientation, porosity, density, and mineralization, on bone strength. J Biomechanics. 22(5). 419-426.

McCalden, R.W., McGeogh, J.A., Barker, M.B., et al. (1993). Age-related changes in the tensile properties of cortical bone. Journal of Bone and Joint Surgery. 75(8), 11931205.

McElhaney, J.H. and Byars, E.F. (1965). Dynamic response of biological materials. ASME. Publ. 65-WA/Huf-9.

McElhaney, J.H., Fogel, J.L., Melvin, J.W., et al. (1970). Mechanical properties of cranial bone. J. Biomechanics. 3, 495-511.

Muellar, K.H., Trias, A., and Ray, R.D. (1966). Bone density and composition. Agerelated and phathological changes in water and mineralization content. J. Bone and Joint Surg. 48-A, 140-148.

Patrick, L.M. (1976). Frontal force impact tolerance of the human thorax. The Human Thorax- Anatomoy, Injury, and Biomechanics, SAE P-67, Dearborn, MI. 37-48.

Ramet, M., and Cesari, D. (1979) Behavior of restrained dummies and cadavers in frontal impacts. Proc. $7^{\text {th }}$ International Research Council on the Biomechanics of Impact: 210219.

Reilly, D.T., Burstein, A.H., and Victor, H.F. (1974). The elastic modulus for bone. $J$ Biomechanics. 7, 271-275.

Reilly, D.T., Burstein, A.H. (1975). The elastic and ultimate properties of compact bone tissue. J Biomechanics. 8(6), 393-405.

Saha, S., and Hayes, W.C. (1974). Instrumented tensile impact tests of bone. Exp. Mecha. 14, 473-478.

Saha, S., and Hayes, W.C. (1976). Tensile impact properties of human compact bone. $J$. Biomechanics. 9, 243-251. 
Schaffler, M.B., and Burr, D.B. (1988). Stiffness of compact bone: effects of porosity and density. J. Biomechanics. 21(1). 13-16.

Schneider, L.W., King, A.L., and Beebe, M.S., (1988). Design requirements and specifications; thorax-abdomen development task. Interim report: Trauma Assessment Device Development Program. Report No, DOT-HS-807-511.1989.

Stitzel, J.D., Cormier, J.M., Barretta, J.T., Kennedy, E.A., Smith, E.P., Rath, A.L, and Duma, S.M. (2003). Defining regional variation in the material properties of human rib cortical bone and its effect on fracture prediction. Proc. $47^{\text {th }}$ Stapp Car Crash Conference. 243- 265. Society of Automotive Engineers, Warrendale, PA.

Wright, T.M., and Hayes, W.C. (1976). Tensile testing of bone over a wide range of strain rates: effects of strain rate, microstructure, and density. Medical and Biological Engineering. Nov. 671-679.

Wood, J.L. (1971). Dynamic response of human cranial bone. J. Biomechanics. 4, 1-12.

Yeni, Y.N., Brown, C.U, and Norman, T.L. (1998). Influence of bone composition and apparent density on fracture toughness of the human femur and tibia. Bone. 22(1). 79 84.

Yeuheui, H.A. and Draughn, R.A. (2000). Mechanical testing of bone and the boneimplant interface. CRC Press LLC, New York.

Yoganandan, N., and Pintar, F.A. (1998). Biomechanics of human thoracic ribs. J. of Biomechanical Engineering. 120: 100-104. 


\section{APPENDIX A}

Table A 1: Material Properties for Cadaver 1.

\begin{tabular}{|c|c|c|c|c|c|c|c|c|}
\hline \multirow[b]{2}{*}{ Specimen } & \multicolumn{3}{|c|}{ Active Area } & \multirow{2}{*}{$\begin{array}{c}\text { Modulus } \\
\text { E } \\
(\mathrm{GPa})\end{array}$} & \multirow{2}{*}{$\begin{array}{c}\text { Strain } \\
\text { Rate } \\
\text { (strain/s) }\end{array}$} & \multirow{2}{*}{$\begin{array}{c}\text { Ultimate } \\
\text { Stress } \\
(\mathrm{MPa})\end{array}$} & \multirow{2}{*}{$\begin{array}{l}\text { Ultimate } \\
\text { Strain } \\
\text { (mstr) }\end{array}$} & \multirow{2}{*}{$\begin{array}{c}\text { SED } \\
\text { (MPa-mstr) }\end{array}$} \\
\hline & $\begin{array}{l}\text { Width } \\
\text { (mm) }\end{array}$ & $\begin{array}{c}\text { Thickness } \\
\text { (mm) }\end{array}$ & $\begin{array}{c}\text { Area } \\
\left(\mathrm{mm}^{2}\right)\end{array}$ & & & & & \\
\hline Cad1-3A & 2.642 & 0.330 & 0.872 & 14.88 & 0.508 & $*$ & * & $*$ \\
\hline Cad1-3L & 2.642 & 0.508 & 1.342 & 16.44 & 0.377 & 155.37 & 36064 & 638450 \\
\hline Cad1-3P & 2.616 & 0.279 & 0.731 & 19.63 & 0.547 & 150.41 & 20789 & 2322200 \\
\hline Cad1-4L & 2.540 & 0.279 & 0.710 & 30.12 & 0.434 & 247.35 & 22208 & 4074200 \\
\hline Cad1-4P & 2.616 & 0.203 & 0.532 & 19.07 & 0.367 & $*$ & $*$ & $*$ \\
\hline Cad1-5A & 2.616 & 0.203 & 0.532 & 16.73 & 0.546 & 131.84 & 18404 & 1728300 \\
\hline Cad1-5L & 2.286 & 0.279 & 0.639 & 11.56 & 0.644 & 71.57 & 11271 & 546570 \\
\hline Cad1-5P & 2.540 & 0.381 & 0.968 & 20.35 & 0.286 & $*$ & $*$ & $*$ \\
\hline Cad1-6A & 2.540 & 0.381 & 0.968 & 9.42 & 0.712 & 86.43 & 13471 & 819050 \\
\hline Cad1-6L & 2.388 & 0.432 & 1.031 & 14.44 & 0.545 & 152.24 & 27903 & 3249600 \\
\hline Cad1-6P & 2.413 & 0.508 & 1.226 & 21.66 & 0.237 & $*$ & $*$ & $*$ \\
\hline Cad1-7A & 2.464 & 0.279 & 0.688 & 18.76 & 0.486 & 73.11 & 5217 & 227390 \\
\hline Cad1-7L & 2.540 & 0.432 & 1.097 & 17.81 & 0.133 & $*$ & $*$ & * \\
\hline Cad1-7P & 2.489 & 0.584 & 1.454 & 9.81 & 0.389 & $*$ & $*$ & $*$ \\
\hline Cad1-8L & 2.235 & 0.279 & 0.625 & 17.68 & 0.421 & $*$ & $*$ & $*$ \\
\hline Cad1-8P & 2.591 & 0.279 & 0.724 & 15.31 & 0.324 & 78.38 & 5665 & 239560 \\
\hline Cad1-9L & 2.591 & 0.406 & 1.053 & 13.57 & 0.388 & 108.04 & 10172 & 644600 \\
\hline Cad1-9P & 2.591 & 0.432 & 1.119 & 10.79 & 0.392 & $*$ & $*$ & $*$ \\
\hline Cad1-10P & 2.692 & 0.406 & 1.094 & 19.67 & 0.533 & 143.26 & 26114 & 2845800 \\
\hline Cad1-11P & 2.515 & 0.279 & 0.703 & 16.02 & 0.737 & 145.82 & 28120 & 3078500 \\
\hline Cad1-12P & 2.540 & 0.279 & 0.710 & 13.68 & 0.496 & 81.91 & 6886 & 313880 \\
\hline
\end{tabular}

* break was not in the measured area of the specimen 
Table A 2: Material Properties for Cadaver 2.

\begin{tabular}{|c|c|c|c|c|c|c|c|c|}
\hline \multirow[b]{2}{*}{ Specimen } & \multicolumn{3}{|c|}{ Active Area } & \multirow{2}{*}{$\begin{array}{c}\text { Modulus } \\
\text { E } \\
\text { (GPa) }\end{array}$} & \multirow{2}{*}{$\begin{array}{l}\text { Strain } \\
\text { Rate } \\
\text { (strain/s) }\end{array}$} & \multirow{2}{*}{$\begin{array}{l}\text { Ultimate } \\
\text { Stress } \\
\text { (MPa) }\end{array}$} & \multirow{2}{*}{$\begin{array}{l}\text { Ultimate } \\
\text { Strain } \\
\text { (mstr) }\end{array}$} & \multirow{2}{*}{$\begin{array}{c}\text { SED } \\
\text { (MPa-mstr) }\end{array}$} \\
\hline & $\begin{array}{l}\text { Width } \\
\text { (mm) }\end{array}$ & $\begin{array}{c}\text { Thickness } \\
\text { (mm) }\end{array}$ & $\begin{array}{c}\text { Area } \\
\left(\mathrm{mm}^{2}\right)\end{array}$ & & & & & \\
\hline Cad2-2P & 2.794 & 0.203 & 0.568 & 12.92 & 0.879 & 98.61 & 14185 & 939190 \\
\hline Cad2-3A & 2.184 & 0.178 & 0.388 & 18.16 & 0.774 & 192.47 & 41637 & 6245700 \\
\hline Cad2-3L & 2.743 & 0.229 & 0.627 & 14.57 & 0.720 & 123.03 & 18790 & 1611600 \\
\hline Cad2-3P & 2.337 & 0.203 & 0.475 & 15.04 & 0.736 & 178.45 & 51860 & 6961800 \\
\hline Cad2-4A & 2.642 & 0.203 & 0.537 & 11.64 & 0.441 & * & $*$ & * \\
\hline Cad2-4L & 2.159 & 0.178 & 0.384 & 14.86 & 0.901 & 157.27 & 29096 & 3396500 \\
\hline Cad2-4P & 2.286 & 0.203 & 0.465 & 15.60 & 0.760 & 134.35 & 22363 & 2146400 \\
\hline Cad2-5A & 2.540 & 0.305 & 0.774 & 13.35 & 0.450 & 90.01 & 10406 & 613970 \\
\hline Cad2-5L & 2.311 & 0.203 & 0.470 & 13.65 & 0.636 & 132.07 & 21085 & 1952700 \\
\hline Cad2-5P & 2.286 & 0.178 & 0.406 & 9.07 & 0.806 & * & * & * \\
\hline Cad2-6A & 2.261 & 0.178 & 0.402 & 16.10 & 0.622 & 167.67 & 25993 & 3015900 \\
\hline Cad2-6L & 2.413 & 0.203 & 0.490 & 14.50 & 0.770 & 157.49 & 40345 & 4902400 \\
\hline Cad2-6P & 2.540 & 0.330 & 0.839 & 12.09 & 0.585 & 105.65 & 17259 & 1293900 \\
\hline Cad2-7A & 2.489 & 0.381 & 0.948 & 20.35 & 0.406 & 173.07 & 29823 & 3780100 \\
\hline Cad2-7L & 2.819 & 0.457 & 1.289 & 12.46 & 0.781 & 149.41 & 42917 & 2736600 \\
\hline Cad2-7P & 2.616 & 0.432 & 1.130 & 15.87 & 0.279 & * & $*$ & * \\
\hline Cad2-8P & 2.388 & 0.254 & 0.606 & 16.71 & 0.616 & 143.00 & 19841 & 2034900 \\
\hline Cad2-9L & 2.438 & 0.305 & 0.743 & 18.11 & 0.696 & 152.10 & 35489 & 4165100 \\
\hline Cad2-9P & 2.464 & 0.203 & 0.501 & 16.03 & 0.587 & 134.61 & 20662 & 2018400 \\
\hline Cad2-10P & 2.464 & 0.229 & 0.563 & 16.80 & 0.637 & 156.55 & 27989 & 3263600 \\
\hline Cad2-11P & 2.515 & 0.330 & 0.830 & 11.21 & 0.408 & 106.91 & 12007 & 765500 \\
\hline
\end{tabular}

* break was not in the measured area of the specimen 
Table A 3: Material Properties for Cadaver 3.

\begin{tabular}{|c|c|c|c|c|c|c|c|c|}
\hline \multirow[b]{2}{*}{ Specimen } & \multicolumn{3}{|c|}{ Active Area } & \multirow{2}{*}{$\begin{array}{c}\text { Modulus } \\
\text { E } \\
\text { (GPa) }\end{array}$} & \multirow{2}{*}{$\begin{array}{c}\text { Strain } \\
\text { Rate } \\
\text { (strain/s) }\end{array}$} & \multirow{2}{*}{$\begin{array}{l}\text { Ultimate } \\
\text { Stress } \\
\text { (MPa) }\end{array}$} & \multirow{2}{*}{$\begin{array}{l}\text { Ultimate } \\
\text { Strain } \\
\text { (mstr) }\end{array}$} & \multirow{2}{*}{$\begin{array}{c}\text { SED } \\
\text { (MPa-mstr) }\end{array}$} \\
\hline & $\begin{array}{l}\text { Width } \\
\text { (mm) }\end{array}$ & $\begin{array}{c}\text { Thickness } \\
\text { (mm) }\end{array}$ & $\begin{array}{c}\text { Area } \\
\left(\mathrm{mm}^{2}\right)\end{array}$ & & & & & \\
\hline Cad3-3A & 2.337 & 0.229 & 0.534 & 12.51 & 0.540 & 91.37 & 10771 & 608210 \\
\hline Cad3-3L & 2.413 & 0.330 & 0.797 & 13.41 & 0.391 & 102.47 & 18201 & 1377400 \\
\hline Cad3-3P & 2.235 & 0.279 & 0.625 & 12.97 & 0.625 & 103.23 & 14012 & 953610 \\
\hline Cad3-4A & 2.438 & 0.203 & 0.495 & 16.62 & 0.474 & 126.98 & 14654 & 124000 \\
\hline Cad3-4L & 2.438 & 0.229 & 0.557 & 17.59 & 0.434 & $*$ & $*$ & $*$ \\
\hline Cad3-4P & 2.489 & 0.229 & 0.569 & 16.25 & 0.458 & 121.72 & 13950 & 1131500 \\
\hline Cad3-5A & 2.362 & 0.178 & 0.420 & 13.80 & 0.439 & 127.08 & 16227 & 1303200 \\
\hline Cad3-5L & 2.388 & 0.203 & 0.485 & 12.63 & 0.514 & 119.57 & 19554 & 1606900 \\
\hline Cad3-5P & 2.540 & 0.203 & 0.516 & 15.76 & 0.697 & 148.43 & 25613 & 2788400 \\
\hline Cad3-6A & 2.362 & 0.229 & 0.540 & 15.71 & 0.690 & 127.34 & 23436 & 2172500 \\
\hline Cad3-6L & 2.591 & 0.203 & 0.526 & 11.80 & 0.660 & 98.06 & 15634 & 1004000 \\
\hline Cad3-6P & 2.540 & 0.203 & 0.516 & 21.20 & 0.487 & $*$ & $*$ & $*$ \\
\hline Cad3-7A & 2.540 & 0.305 & 0.774 & 15.84 & 0.580 & 142.68 & 26578 & 2848700 \\
\hline Cad3-7L & 2.540 & 0.229 & 0.581 & 15.12 & 0.672 & 14.21 & 21772 & 224570 \\
\hline Cad3-8L & 2.540 & 0.305 & 0.774 & 13.70 & 0.621 & 136.47 & 25368 & 2481800 \\
\hline Cad3-9P & 2.489 & 0.229 & 0.569 & 9.44 & 0.638 & $*$ & $*$ & $*$ \\
\hline Cad3-10P & 2.540 & 0.305 & 0.774 & 12.17 & 0.588 & 101.35 & 16794 & 1187800 \\
\hline
\end{tabular}

* break was not in the measured area of the specimen 
Table A 4: Material Properties for Cadaver 4.

\begin{tabular}{|c|c|c|c|c|c|c|c|c|}
\hline \multirow[b]{2}{*}{ Specimen } & \multicolumn{3}{|c|}{ Active Area } & \multirow{2}{*}{$\begin{array}{c}\text { Modulus } \\
\text { E } \\
(\mathrm{GPa})\end{array}$} & \multirow{2}{*}{$\begin{array}{c}\text { Strain } \\
\text { Rate } \\
\text { (strain/s) }\end{array}$} & \multirow{2}{*}{$\begin{array}{l}\text { Ultimate } \\
\text { Stress } \\
\text { (MPa) }\end{array}$} & \multirow{2}{*}{$\begin{array}{l}\text { Ultimate } \\
\text { Strain } \\
\text { (mstr) }\end{array}$} & \multirow{2}{*}{$\begin{array}{c}\text { SED } \\
\text { (MPa-mstr) }\end{array}$} \\
\hline & $\begin{array}{l}\text { Width } \\
\text { (mm) }\end{array}$ & $\begin{array}{c}\text { Thickness } \\
\text { (mm) }\end{array}$ & $\begin{array}{c}\text { Area } \\
\left(\mathrm{mm}^{2}\right)\end{array}$ & & & & & \\
\hline Cad4-3A & 2.591 & 0.203 & 0.526 & 15.70 & 0.618 & 154.42 & 35332 & 4059000 \\
\hline Cad4-3L & 2.616 & 0.483 & 1.263 & 14.52 & 0.454 & 143.21 & 31069 & 3374400 \\
\hline Cad4-3P & 2.642 & 0.330 & 0.872 & 13.26 & 0.583 & 131.30 & 25762 & 2450600 \\
\hline Cad4-4A & 2.565 & 0.229 & 0.586 & 14.97 & 0.646 & 152.57 & 36077 & 4164300 \\
\hline Cad4-4L & 2.616 & 0.432 & 1.130 & 16.63 & 0.349 & 174.14 & 27386 & 3468900 \\
\hline Cad4-4P & 2.565 & 0.305 & 0.782 & 14.40 & 0.381 & 121.56 & 16482 & 1389600 \\
\hline Cad4-5A & 2.540 & 0.279 & 0.710 & 12.78 & 0.418 & 151.90 & 29876 & 3218000 \\
\hline Cad4-5L & 2.667 & 0.330 & 0.881 & 17.24 & 0.653 & 136.51 & 21804 & 2181200 \\
\hline Cad4-6A & 2.565 & 0.381 & 0.977 & 18.26 & 0.312 & * & * & * \\
\hline Cad4-6L & 2.616 & 0.381 & 0.997 & 14.89 & 0.317 & 116.98 & 13519 & 1067800 \\
\hline Cad4-6P & 2.591 & 0.432 & 1.119 & 11.87 & 0.395 & 136.49 & 26274 & 2510800 \\
\hline Cad4-7A & 2.616 & 0.203 & 0.532 & 15.91 & 0.698 & 170.56 & 45858 & 5976600 \\
\hline Cad4-7L & 2.565 & 0.330 & 0.847 & 12.86 & 0.589 & 124.78 & 18873 & 1664700 \\
\hline Cad4-8L & 2.540 & 0.305 & 0.774 & 12.20 & 0.515 & * & * & * \\
\hline Cad4-8P & 2.565 & 0.330 & 0.847 & 14.92 & 0.370 & 155.37 & 36064 & 4250200 \\
\hline Cad4-9L & 2.565 & 0.406 & 1.043 & 14.64 & 0.555 & 153.11 & 47954 & 5727600 \\
\hline Cad4-9P & 2.591 & 0.432 & 1.119 & 13.44 & 0.409 & 144.64 & 26159 & 2773200 \\
\hline Cad4-10P & 2.616 & 0.483 & 1.263 & 18.34 & 0.233 & 144.64 & 26159 & 2367000 \\
\hline Cad4-11P & 2.565 & 0.356 & 0.912 & 11.83 & 0.607 & 144.66 & 33793 & 3576700 \\
\hline
\end{tabular}

* break was not in the measured area of the specimen 
Table A 5: Material Properties for Cadaver 5.

\begin{tabular}{|c|c|c|c|c|c|c|c|c|}
\hline \multirow[b]{2}{*}{ Specimen } & \multicolumn{3}{|c|}{ Active Area } & \multirow{2}{*}{$\begin{array}{c}\text { Modulus } \\
\text { E } \\
\text { (GPa) }\end{array}$} & \multirow{2}{*}{$\begin{array}{l}\text { Strain } \\
\text { Rate } \\
\text { (strain/s) }\end{array}$} & \multirow{2}{*}{$\begin{array}{l}\text { Ultimate } \\
\text { Stress } \\
\text { (MPa) }\end{array}$} & \multirow{2}{*}{$\begin{array}{l}\text { Ultimate } \\
\text { Strain } \\
\text { (mstr) }\end{array}$} & \multirow{2}{*}{$\begin{array}{c}\text { SED } \\
\text { (MPa-mstr) }\end{array}$} \\
\hline & $\begin{array}{l}\text { Width } \\
\text { (mm) }\end{array}$ & $\begin{array}{c}\text { Thickness } \\
\text { (mm) }\end{array}$ & $\begin{array}{c}\text { Area } \\
\left(\mathrm{mm}^{2}\right)\end{array}$ & & & & & \\
\hline Cad5-1L & 2.616 & 0.254 & 0.665 & 9.59 & 0.506 & * & * & * \\
\hline Cad5-3P & 2.540 & 0.305 & 0.774 & 20.89 & 0.334 & * & $*$ & * \\
\hline Cad5-4L & 2.362 & 0.254 & 0.600 & 18.95 & 0.515 & 129.30 & 14305 & 1255500 \\
\hline Cad5-4P & 2.362 & 0.305 & 0.720 & 8.88 & 0.571 & $*$ & $*$ & $*$ \\
\hline Cad5-5A & 3.175 & 0.203 & 0.645 & 7.91 & 0.664 & $*$ & * & $*$ \\
\hline Cad5-5L & 2.464 & 0.305 & 0.751 & 12.95 & 0.641 & 95.90 & 14317 & 878860 \\
\hline Cad5-6A & 2.591 & 0.305 & 0.790 & 11.19 & 0.476 & * & * & * \\
\hline Cad5-6L & 2.540 & 0.432 & 1.097 & 14.17 & 0.381 & 115.98 & 16264 & 1313100 \\
\hline Cad5-6P & 2.464 & 0.483 & 1.189 & 18.06 & 0.159 & 132.40 & 8373 & 636540 \\
\hline Cad5-7A & 2.616 & 0.254 & 0.665 & 14.42 & 0.371 & $*$ & $*$ & * \\
\hline Cad5-7L & 2.591 & 0.279 & 0.724 & 18.28 & 0.369 & 125.93 & 12081 & 1017300 \\
\hline Cad5-7P & 2.591 & 0.381 & 0.987 & 18.97 & 0.090 & $*$ & $*$ & $*$ \\
\hline Cad5-8L & 2.413 & 0.381 & 0.919 & 14.94 & 0.698 & 126.34 & 23114 & 2215500 \\
\hline Cad5-8P & 2.489 & 0.279 & 0.695 & 14.37 & 0.328 & 119.22 & 12284 & 874990 \\
\hline Cad5-9L & 2.642 & 0.381 & 1.006 & 15.60 & 0.394 & 89.29 & 15537 & 1027200 \\
\hline Cad5-9P & 2.794 & 0.381 & 1.065 & 12.66 & 0.239 & $*$ & $*$ & $*$ \\
\hline Cad5-10P & 2.438 & 0.254 & 0.619 & 11.33 & 0.451 & 95.47 & 14232 & 895300 \\
\hline Cad5-11P & 2.362 & 0.330 & 0.780 & 11.13 & 0.485 & 83.32 & 17372 & 1006500 \\
\hline
\end{tabular}

* break was not in the measured area of the specimen 
Table A 6: Material Properties for Cadaver 6.

\begin{tabular}{|c|c|c|c|c|c|c|c|c|}
\hline \multirow[b]{2}{*}{ Specimen } & \multicolumn{3}{|c|}{ Active Area } & \multirow{2}{*}{$\begin{array}{c}\text { Modulus } \\
\text { E } \\
\text { (GPa) }\end{array}$} & \multirow{2}{*}{$\begin{array}{l}\text { Strain } \\
\text { Rate } \\
\text { (strain/s) }\end{array}$} & \multirow{2}{*}{$\begin{array}{l}\text { Ultimate } \\
\text { Stress } \\
\text { (MPa) }\end{array}$} & \multirow{2}{*}{$\begin{array}{l}\text { Ultimate } \\
\text { Strain } \\
\text { (mstr) }\end{array}$} & \multirow{2}{*}{$\begin{array}{c}\text { SED } \\
\text { (MPa-mstr) }\end{array}$} \\
\hline & $\begin{array}{l}\text { Width } \\
\text { (mm) }\end{array}$ & $\begin{array}{c}\text { Thickness } \\
\text { (mm) }\end{array}$ & $\begin{array}{c}\text { Area } \\
\left(\mathrm{mm}^{2}\right)\end{array}$ & & & & & \\
\hline Cad6-1L & 2.616 & 0.432 & 1.130 & 12.92 & 0.469 & 143.52 & 50599 & 5622600 \\
\hline Cad6-2L & 2.565 & 0.254 & 0.652 & 6.86 & 0.711 & 79.22 & 26603 & 1525900 \\
\hline Cad6-2P & 2.489 & 0.203 & 0.506 & 8.15 & 0.735 & 109.00 & 43604 & 3413000 \\
\hline Cad6-3P & 2.616 & 0.432 & 1.130 & 10.20 & 0.500 & 130.37 & 64765 & 6322400 \\
\hline Cad6-4A & 2.565 & 0.254 & 0.652 & 8.10 & 0.691 & 86.19 & 60608 & 3987100 \\
\hline Cad6-4L & 2.616 & 0.584 & 1.528 & 8.45 & 0.450 & 102.73 & 52150 & 4105700 \\
\hline Cad6-4P & 2.642 & 0.584 & 1.543 & 10.72 & 0.301 & 100.08 & 27699 & 2074500 \\
\hline Cad6-5A & 2.565 & 0.305 & 0.782 & 6.12 & 0.577 & 59.00 & 22872 & 959760 \\
\hline Cad6-5L & 2.642 & 0.787 & 2.080 & 10.96 & 0.470 & 111.51 & 49975 & 4340200 \\
\hline Cad6-5P & 2.616 & 0.787 & 2.060 & 10.46 & 0.575 & 127.39 & 65671 & 6433700 \\
\hline Cad6-6A & 2.642 & 0.203 & 0.537 & 6.13 & 0.466 & $*$ & $*$ & $*$ \\
\hline Cad6-6L & 2.692 & 0.432 & 1.163 & 15.43 & 0.433 & 123.32 & 30450 & 2852300 \\
\hline Cad6-6P & 2.642 & 0.229 & 0.604 & 9.77 & 0.573 & 106.87 & 29346 & 2276900 \\
\hline Cad6-7A & 2.489 & 0.254 & 0.632 & 10.90 & 0.692 & 90.58 & 36355 & 2573000 \\
\hline Cad6-7L & 2.616 & 0.330 & 0.864 & 12.53 & 0.562 & 125.39 & 45190 & 4313100 \\
\hline Cad6-8L & 2.642 & 0.762 & 2.013 & 10.19 & 0.556 & 120.49 & 51693 & 4760400 \\
\hline Cad6-8P & 2.565 & 0.635 & 1.629 & 10.51 & 0.595 & 90.99 & 25129 & 1716600 \\
\hline Cad6-9L & 2.616 & 0.457 & 1.196 & 9.32 & 0.498 & 115.61 & 42195 & 3586500 \\
\hline Cad6-9P & 2.362 & 0.559 & 1.320 & 10.55 & 0.643 & 120.34 & 54108 & 5153400 \\
\hline Cad6-10P & 2.565 & 0.203 & 0.521 & 9.19 & 0.699 & 79.58 & 19397 & 1039000 \\
\hline Cad6-11P & 2.540 & 0.203 & 0.516 & 8.46 & 0.638 & 103.50 & 48918 & 3820800 \\
\hline
\end{tabular}

* break was not in the measured area of the specimen 